\title{
Dynamic hysteresis in monolith reactors and hysteresis effects during co-oxidation of $\mathrm{CO}$ and $\mathrm{C}_{2} \mathrm{H}_{6}$.
}

\author{
Rama Krishna Dadi, Dan Luss and Vemuri Balakotaiah* \\ Department of Chemical and Biomolecular Engineering, University of Houston, Houston, TX-77204, USA
}

March 25, 2016

\begin{abstract}
In many laboratory catalytic reactors light-off curves describing the exit conversion versus inlet gas temperature do not follow the same path during ramp up and ramp down and this leads to dynamic hysteresis. This dynamic hysteresis, which may occur even under ideal conditions (e.g. plug flow and negligible heat effects) is fundamentally different from the steady-state hysteresis which is due to heat effects and thermal feedback. We present expressions for the width of the dynamic hysteresis loop as a function of the ramp rate, solid to gas heat capacity ratio, space time and the heat Peclet number, for the limiting cases of pseudo-homogeneous and two phase plug flow models with negligible heat effects $\left(\Delta T_{a d}=0\right)$. We review the conditions under which steady-state hysteresis can exist for a finite $\Delta T_{a d}$ and demonstrate the combined impact of steady-state and dynamic hysteresis effects. We study the light-off behavior and dynamic hysteresis during the co-oxidation of $\mathrm{CO}+\mathrm{C}_{2} \mathrm{H}_{6}$ mixture on $\mathrm{Pt} / \mathrm{Al}_{2} \mathrm{O}_{3}$. It is found that $1 \%$ of $C O$ alone ignites at $473 \mathrm{~K}$ whereas $500 \mathrm{ppm}$ of $\mathrm{C}_{2} \mathrm{H}_{6}$ alone ignites at $723 \mathrm{~K}$. The exotherm generated by the $\mathrm{CO}$ oxidation can reduce the ignition temperature of $\mathrm{C}_{2} \mathrm{H}_{6}$ during the co-oxidation of $\mathrm{CO}$ and $\mathrm{C}_{2} \mathrm{H}_{6}$. Bifurcation diagrams of solid exit temperature versus fluid inlet temperature for different inlet compositions illustrate the simultaneous as well as separate ignitions for $C O$ and $C_{2} H_{6}$. Each $1 \%$ increase in the $C O$ feed mole percentage decreases $\mathrm{C}_{2} \mathrm{H}_{6}$
\end{abstract}

\footnotetext{
*Corresponding author: email: bala@uh.edu
} 
ignition temperature by about $80^{\circ} \mathrm{C}$. A feed of $3 \% \mathrm{CO}$ is required for simultaneous ignition of a mixture of $\mathrm{CO}$ and 500ppm of $\mathrm{C}_{2} \mathrm{H}_{6}$.

Key words: Dynamic hysteresis, light-off, simultaneous ignition, monolith reactor, steadystate hysteresis. 


\section{Introduction and literature review}

Monolith reactors used in after-treatment of diesel and gasoline engine exhausts consist of long identical channels through which the exhaust gases flow. The substrate of the monoliths used in automobile converters is mainly made up of cordierite, which has a low thermal conductivity. However, metallic monoliths are also being used in recent years. The catalyst materials are deposited on the substrate in thin layers whose thickness is in the range of $15-50 \mu \mathrm{m}$.

In laboratory studies, temperature programmed experiments are widely used to characterize the activity of catalysts and estimate the kinetic constants. These experiments involve heating or cooling of the feed temperature at a linear (ramp) rate and used to determine the light-off curves for various

species. A typical light-off curve describes the dependence of exit conversion on a constant increasing inlet temperature until nearly complete exit conversion. This curve differs from that when the feed temperature is ramped down at the same rate. This hysteresis loop is commonly referred to as dynamic hysteresis. The main applications of the light-off curves obtained by ramping up and down of the feed temperature are the evaluation of the performance of the catalyst, light-off temperatures for various species, characterization of the catalyst surface and determination of the kinetic constants.

Many previous studies investigated the steady state multiplicity features of different reactor systems [1-3]. Harold et al. [4,5] showed that multiplicity features obtained from experiments may be used to qualitatively describe the kinetic features. Ramanathan et al. [6] developed an analytical criterion for light-off in monolith reactors. Gundlapally and Balakotaiah [7] studied the impact of substrate material on the steady state behavior in monolith reactors. Many recent studies [8-10] used transient experiments to elucidate the formation of various surface intermediates on a catalyst surface. In a more recent study, the dynamic hysteresis behavior during $\mathrm{CO}+\mathrm{C}_{3} \mathrm{H}_{6}$ oxidation on a $\mathrm{Pt} / \mathrm{Al}_{2} \mathrm{O}_{3}$ catalyst was investigated by Raj et al. [11]. They showed that dynamic hysteresis could occur even without steady state multiplicity and arose due to delay in the heat transport along the monolith. That work used global kinetics and hence could not examine the impact of surface intermediates formation during the temperature ramp up or down. Further, no detailed analysis of dynamic or steady-state hysteresis has yet been presented. It is essential to understand the difference between dynamic and steady-state hysteresis behavior in order to avoid the misinterpretation of the 
hysteresis due to the transient inlet conditions as being a steady-state multiplicity.

Carbon monoxide and hydrocarbons (HCs) are two of the three main pollutants released by diesel and gasoline engines exhaust. Oxidation catalysts convert the $\mathrm{CO}$ and $\mathrm{HCs}$ to $\mathrm{CO}_{2}$ and $\mathrm{H}_{2} \mathrm{O}$. Several mechanisms have been proposed to explain the competitive oxidation of $\mathrm{CO}, \mathrm{HCs}$ and $\mathrm{H}_{2}$ on noble metal catalysts. Abedi et al. [9] presented experimental data on the hysteresis behavior of $\mathrm{CO}$ oxidation in a $\mathrm{CO}+\mathrm{C}_{3} \mathrm{H}_{6}$ mixture over a $\mathrm{Pt} / \mathrm{Al}_{2} \mathrm{O}_{3}$ catalyst. Sun et al. [12] investigated steady state multiplicity and superadiabatic extinction waves in the oxidation of $\mathrm{CO}+\mathrm{H}_{2}$ mixtures over a $\mathrm{Pt} / \mathrm{Al}_{2} \mathrm{O}_{3}$-coated monolith. Bhatia et al. [13] compared the light-off curves generated using a global model and a microkinetic model and investigated the effect of rate parameters on the region of multiplicity. These studies show that the ignition temperature of $C O$ decreases with either an increase in the feed $\mathrm{H}_{2}$ concentration or a decrease in the feed $\mathrm{CO}$ concentration. The oxidation of $\mathrm{CO}+\mathrm{H}_{2}$ mixture is an example in which ignition of each component in the mixture occurs in the same temperature region. Carlsson et al. [14] studied the ignition and extinction processes for total oxidation of $\mathrm{CO}, \mathrm{CH}_{4}$ and $\mathrm{CO}+\mathrm{CH}_{4}$ mixture in excess oxygen over $\mathrm{Pt} / \mathrm{Al}_{2} \mathrm{O}_{3}$ and $\mathrm{Pt} / \mathrm{CeO}$. The ignition and extinction of $\mathrm{CO}$ and $\mathrm{CH}_{4}$ oxidation in mixture of $\mathrm{CO}$ and $\mathrm{CH}_{4}$ occur in different temperature regions. Several HCs exist in the engine exhaust of automobiles, and each ignites at a different temperature. It is of practical importance to know if the ignition temperatures of the components are either widely different or close to each other. An example of a system in which the light-off temperatures are close is the $\mathrm{CO}+\mathrm{C}_{3} \mathrm{H}_{6}$. A second example is the oxidation of $\mathrm{CO}+\mathrm{C}_{2} \mathrm{H}_{6}$ mixture. In this case, $C O$ ignites at low temperature and $C_{2} H_{6}$ ignites at a much higher temperature.

The main objectives of this work are: (i) to study the dependence of ramp rate, thermal properties and operating conditions on the width of the dynamic hysteresis loop, (ii) to examine the impact of interphase and intraphase temperature gradients on the dynamic hysteresis, (iii) to review and extend literature results on the impact of inter and intraphase gradients on the steady-state hysteresis and combined steady-state and dynamic hysteresis, and (iv) to examine the light-off behavior of a $\mathrm{CO}+\mathrm{C}_{2} \mathrm{H}_{6}$ mixture on $\mathrm{Pt} / \mathrm{Al}_{2} \mathrm{O}_{3}$ catalyst. This paper is organized as follows. A general mathematical model and a simplified non-dimensionalised model are presented in the next section. The dynamic hysteresis behavior using pseudo-homogeneous model and two-phase plug flow model are analyzed in section 3. Numerical simulations that elucidate the dynamic hysteresis effects in monolith reactors 
are presented in section 4. An analysis and simulation of steady-state hysteresis effects and combined steady-state plus dynamic hysteresis are presented in section 5 . The co-oxidation behavior of $C O+$ $\mathrm{C}_{2} \mathrm{H}_{6}$ is studied by numerical simulations in section 6 . The last section summarizes the main results with a discussion of their relevance to the design of low temperature exhaust after-treatment systems.

\section{Model description}

A low-dimensional model of a catalytic monolith channel with washcoat diffusion is used in this study. This model is derived by averaging the governing equations and using the concepts of internal and external mass transfer coefficients. It accounts for washcoat diffusion effects without solving the multi-component diffusion-reaction problem in the washcoat. The low-dimensional model reduces the computational effort while retaining all the essential features of the convection-diffustion-reaction problem. The details of the model are presented in Joshi et al. [15-17]. We consider a single straight channel in which catalyst activity and washcoat distribution (average thickness) do not vary in the flow direction. The main assumptions of this model are: (i) pressure drop is negligible, (ii) the wall as well as the washcoat thickness are small compared to the channel hydraulic radius, (In general, the washcoat thickness may not be uniform in the circumferential direction of the channel. For example, in a square channel, the washcoat thickness may vary from a minimum of $10 \mu \mathrm{m}$ in the middle to a maximum of $100 \mu \mathrm{m}$ at the corners. However, as shown by Bhattacharya et al. [18], assuming an average thickness introduces a very small error) (iii) The hydraulic diameter of the channel is much smaller than the length of the channel, (iv) axial conduction/diffusion term can be neglected in the fluid phase compared to the convective transport, (v) the flow is laminar and fully developed. We note that assumption (iii) justifies assumptions (iv) and (v). Assumption (v) may justify the use of constant heat and mass transfer coefficients. However, if the flow enters the channel fully developed but the residence time is comparable to the transverse diffusion time, we cannot neglect the boundary layer formed near the entrance. Therefore, the low-dimensional model should be used with position dependent mass and heat transfer coefficients. 


\subsection{Mathematical model}

The species balance in the fluid phase is

$$
\frac{\partial Y_{f m, j}}{\partial t}+\langle u\rangle \frac{\partial Y_{f m, j}}{\partial z^{\prime}}=-\frac{1}{R_{\Omega_{1}}} k_{m o, j}\left(z^{\prime}\right)\left(Y_{f m, j}-\left\langle Y_{w c}\right\rangle_{j}\right) ; \quad j=1,2, . ., S
$$

where $Y_{f m, j}$ and $\left\langle Y_{w c}\right\rangle_{j}$ are the cup-mixing mole-fraction of species $j$ in the fluid phase and volume averaged mole-fraction of species $j$ in the interstitial spaces of the washcoat, respectively; $R_{\Omega_{1}}$ is the hydraulic radius defined as the ratio of the channel area (open to flow) to fluid-solid interfacial perimeter, and $k_{m o, j}\left(z^{\prime}\right)$ is the overall mass transfer coefficient of species $j$ given by

$$
\frac{1}{k_{m o, j}\left(z^{\prime}\right)}=\frac{1}{k_{m i, j}}+\frac{1}{k_{m e,, j}\left(z^{\prime}\right)}
$$

where $k_{m i, j}$ and $k_{m e, j}$ are the internal and external mass transfer coefficients, respectively. These mass transfer coefficients are computed using the relations

$$
k_{m e, j}=\frac{S h_{e}\left(z^{\prime}\right) D_{f, j}}{4 R_{\Omega_{1}}} ; \quad k_{m i, j}=\frac{S h_{i, \infty} D_{e, j}}{R_{\Omega_{2}}}
$$

where $D_{f, j}$ and $D_{e, j}$ are the diffusivities of species $j$ in the fluid phase and washcoat phase, respectively. The effective diffusivity in the washcoat is estimated by assuming a constant diffusivity ratio $\left(\lambda=D_{e, j} / D_{f, j}=0.01\right)$. Here, $R_{\Omega_{2}}$ is the effective transverse diffusion length in the washcoat defined as the ratio of washcoat cross-sectional area to the fluid-washcoat interfacial perimeter (i.e. $R_{\Omega_{2}}$ is the effective average washcoat thickness). The position dependent transfer coefficient or Sherwood number $S h_{e}\left(z^{\prime}\right)$ is taken from the work of Ramanathan et al. [6]. Heat and mass transfer coefficients are considered for a fully developed flow. The internal mass transfer coefficient for species $\mathrm{j}$ is approximated by using the asymptotic internal Sherwood number $S h_{i, \infty}[15]$.

The species balance in the solid phase is given by

$$
\epsilon_{w c} R_{\Omega_{2}} \frac{\partial\left\langle Y_{w c}\right\rangle_{j}}{\partial t}=k_{m o, j}\left(z^{\prime}\right)\left(Y_{f m, j}-\left\langle Y_{w c}\right\rangle_{j}\right)+\frac{R_{\Omega_{2}}}{C_{0}} \sum_{i=1}^{N} v_{i j} R_{i}\left(\left\langle Y_{w c}\right\rangle_{j}, T_{s}\right)
$$

where $\epsilon_{w c}, v_{i j}$ and $R_{i}$ represent the washcoat porosity, stoichiometric coefficients of species $\mathrm{j}$ in reaction $\mathrm{i}$ and volumetric reaction rate (per unit washcoat volume) of reaction $\mathrm{i}$, respectively. $T_{s}$ is 
the solid temperature. The total concentration in the gas phase $C_{0}$ is approximated by using the ideal gas law $\left[C_{0}=\frac{P_{0}}{R_{g} T} ; P_{0}=101325 \mathrm{~Pa}\right]$ and neglecting pressure drop in the channel

The energy balance equations in fluid and washcoat phases are given by

$$
\begin{gathered}
\rho_{f} c_{p f} \frac{\partial T_{f}}{\partial t}+\langle u\rangle \rho_{f} c_{p f} \frac{\partial T_{f}}{\partial z^{\prime}}=\frac{h\left(z^{\prime}\right)}{R_{\Omega_{1}}}\left(T_{s}-T_{f}\right) \\
R_{\Omega_{w}} \rho_{w} c_{p w} \frac{\partial T_{s}}{\partial t}=R_{\Omega_{w}} k_{w} \frac{\partial^{2} T_{s}}{\partial z^{\prime 2}}+h\left(z^{\prime}\right)\left(T_{f}-T_{s}\right) R_{\Omega_{2}}+R_{\Omega_{2}} \sum_{i=1}^{N} R_{i}\left(\left\langle Y_{w c}\right\rangle_{j}, T_{s}\right)\left(-\Delta H_{i}\right),
\end{gathered}
$$

where $\rho_{f}, c_{p f}, h, T_{f}, T_{s}$ are the gas density, specific heat capacity, heat transfer coefficient, gas phase temperature and solid (washcoat + support) temperature, respectively. Here, $N$ is the number of reactions. The effective solid phase (wall) heat capacity and thermal conductivity are computed as $R_{\Omega_{w}} \rho_{w} c_{p w}=R_{\Omega_{2}} \rho_{c} c_{p c}+R_{\Omega_{s}} \rho_{s} c_{p s}$ and $R_{\Omega_{w}} k_{w}=R_{\Omega_{2}} k_{c}+R_{\Omega_{s}} k_{s}$, respectively. The subscripts c and s refer to catalyst and support, respectively.

The initial conditions are:

$$
\begin{gathered}
Y_{f m, j}\left(z^{\prime}, t=0\right)=Y_{f m, j 0}\left(z^{\prime}\right) \\
\left\langle Y_{w c}\right\rangle_{j}\left(z^{\prime}, t=0\right)=\left\langle Y_{w c}\right\rangle_{j 0}\left(z^{\prime}\right) \\
T_{f}\left(z^{\prime}, t=0\right)=T_{f 0}\left(z^{\prime}\right) \\
T_{s}\left(z^{\prime}, t=0\right)=T_{s 0}\left(z^{\prime}\right) .
\end{gathered}
$$

The inlet/boundary conditions are:

$$
\begin{aligned}
Y_{f m}\left(z^{\prime}\right. & =0, t)=Y_{f}^{i n}(t) \\
T_{f}\left(z^{\prime}\right. & =0, t)=T_{f}^{i n}(t) \\
\frac{\partial T_{s}}{\partial z}\left(z^{\prime}\right. & =0, t)=0 ; \frac{\partial T_{s}}{\partial z}\left(z^{\prime}=L, t\right)=0
\end{aligned}
$$

All the numerical simulations use the above low-dimensional model. However, the analysis of dynamic hysteresis behavior is done using a non-dimensionalised form of the model with a single 
reaction. To simplify the analysis of the dynamic hysteresis, diffusional limitations in the washcoat are neglected. This assumption allows us to approximate the overall mass transfer coefficient with an external mass transfer coefficient. The simplified non-dimensionalized version of the model for the single reaction case is

$$
\begin{gathered}
\frac{\partial Y_{m}}{\partial \tau}+\frac{\partial Y_{m}}{\partial z}=-\frac{S h_{\Omega}(z)}{P}\left(Y_{m}-Y_{s}\right) \\
\frac{\epsilon_{w c}}{\varsigma} \frac{\partial Y_{s}}{\partial \tau}=\frac{S h_{\Omega}(z)}{P}\left(Y_{m}-Y_{s}\right)-\operatorname{DaR}\left(Y_{s}, \theta_{s}\right) \\
\sigma \frac{\partial \theta_{s}}{\partial \tau}=\frac{1}{P e_{h}} \frac{\partial^{2} \theta_{s}}{\partial z^{2}}-\frac{L e_{f} N u_{\Omega}(z)}{P}\left(\theta_{s}-\theta_{m}\right)+\beta \operatorname{DaR}\left(Y_{s}, \theta_{s}\right) \\
\frac{\partial \theta_{m}}{\partial \tau}+\frac{\partial \theta_{m}}{\partial z}=\frac{L e_{f} N u_{\Omega}(z)}{P}\left(\theta_{s}-\theta_{m}\right)
\end{gathered}
$$

where $\quad z=\frac{z^{\prime}}{L} ; \tau=\frac{t}{t_{0}} ; \quad t_{0}=\frac{L}{\langle u\rangle} ; \quad \theta=\frac{T-T_{r e f}}{T_{r e f}} ; \quad \sigma=\frac{R_{\Omega_{2}} \rho_{c} c_{p c}+R_{\Omega_{s}} \rho_{s} c_{p s}}{\rho_{f} c_{p f} R_{\Omega_{1}}}$

$$
\begin{aligned}
P e_{h} & =\frac{\langle u\rangle L \rho_{f} c_{p f} R_{\Omega_{1}}}{R_{\Omega_{w}} k_{w}} ; \quad P=\frac{\langle u\rangle R_{\Omega_{1}}^{2}}{L D_{m}} ; \quad \varsigma=\frac{R_{\Omega_{1}}}{R_{\Omega_{2}}} ; \\
L e_{f} & =\frac{k_{f}}{\rho_{f} c_{p f D_{m}}} ; \quad P_{h}=\frac{P}{L e_{f}} ; D a=\frac{L R_{v}\left(Y_{i n,} T_{r e f}\right) R_{\Omega_{2}}}{\langle u\rangle C_{o} R_{\Omega_{1}}} ; \quad R\left(Y_{s}, \theta_{s}\right)=\frac{R_{v}\left(Y_{s} T_{r e f}\left(1+\theta_{s}\right)\right)}{R_{v}\left(Y_{i n} T_{r e f}\right)} \\
S h_{\Omega}(z) & =\frac{k_{c}(L z) R_{\Omega_{1}}}{D_{m}} ; \quad N u_{\Omega}(z)=\frac{h(L z) R_{\Omega_{1}}}{k_{f}} ; \quad \Delta T_{a d}=\frac{\left(-\Delta H_{R}\right) C_{o}}{\rho_{f} c_{p f}} ; \quad \beta=\frac{\Delta T_{a d}}{T_{r e f}}
\end{aligned}
$$

The corresponding initial, inlet and boundary conditions are

$$
\begin{gathered}
Y_{m}(z, 0)=Y_{m 0}(z), Y_{s}(z, 0)=Y_{s 0}(z), \theta_{m}(z, 0)=\theta_{m 0}(z), \theta_{s}(z, 0)=\theta_{s 0}(z) \\
Y_{m}(0, \tau)=Y_{i n}(\tau), \theta_{m}(0, \tau)=\theta_{i n}(\tau) \\
\frac{\partial \theta_{s}}{\partial z}(0, \tau)=\frac{\partial \theta_{s}}{\partial z}(1, \tau)=0
\end{gathered}
$$

We use both dimensional and non-dimensional models to study the dynamic hysteresis during $\mathrm{CO}$ oxidation on $\mathrm{Pt} / \mathrm{Al}_{2} \mathrm{O}_{3}$, the rate of which as determined by Raj et al. [11] is.

$$
R_{C O}=\frac{\widehat{k_{C O}} Y_{C O}}{\left(1+K_{C O} Y_{C O}\right)^{2}}
$$


In all the numerical simulations, oxygen is taken to be present in excess in the feed and the feed oxygen mole fraction is taken to be $10 \%$. Thus,

$$
\widehat{k_{C O}}=k_{C O} Y_{O_{2}},
$$

where $k_{C O}$ is the rate constant defined by Eqn.25

The rate expression for ethane oxidation in the co-oxidation of $\mathrm{CO}$ and $\mathrm{C}_{2} \mathrm{H}_{6}$ on $\mathrm{Pt} / \mathrm{Al}_{2} \mathrm{O}_{3}$ as reported by Garetto et al. [19] is

$$
\begin{gathered}
R_{C_{2} H_{6}}=\frac{\widehat{k_{C_{2} H_{6}}} Y_{C_{2} H_{6}}}{\left(1+K_{C O} Y_{C O}\right)^{2}}, \\
\widehat{k_{C_{2} H_{6}}}=k_{C_{2} H_{6}} Y_{O_{2}} \\
k_{C O}=A_{C O} \exp \left(-\frac{E_{C O}}{R_{g} T}\right) ; K_{C O}=A_{I C O} \exp \left(-\frac{\Delta H_{I C O}}{R_{g} T}\right) ; k_{C_{2} H_{6}}=A_{C_{2} H_{6}} \exp \left(-\frac{E_{C_{2} H_{6}}}{R_{g} T}\right)
\end{gathered}
$$

The values of the kinetic parameters are listed in Table 1

The adiabatic temperature rise $\Delta T_{a d}$ as defined above using total concentration $C_{0}$ is a large number. The true adiabatic temperature rise is $\Delta T_{a d} Y_{i n}$, where $Y_{i n}$ is the mole fraction of the limiting reactant.

\section{Dynamic hysteresis with negligible heat of reaction}

We analyze the dynamic hysteresis behavior for a case with negligible heat of reaction $(\beta=0)$ using two limiting models (pseudo-homogeneous and two phase plug flow models). Hysteresis can be the result of a high exotherm generated by the reactions and the delay in the temperature propagation by the transport processes. In this section, the dynamic hysteresis occurring due to the delay in temperature transport is analyzed. A pseudo-homogenous model is a good approximation of the 
detailed model when the interphase (transverse) Peclet number is small. Thus, for a high residence time, high cell density and small $\Delta T_{a d}$ a pseudo-homogeneous model is a good approximation of the detailed model. Interphase gradients become significant when the residence time is low or the cell density is low or $\Delta T_{a d}$ is large. A two-phase plug flow model is used to determine hysteresis caused due to interphase temperature and concentration gradients.

\subsection{Pseudo-homogeneous model}

The parameters region in which the qualitative behavior of a packed bed can be captured by a pseudohomogeneous model was determined by Dommeti et al. [21]. We use that model to predict the dynamic hysteresis behavior when the interphase gradients between the solid and fluid are negligible. When the interphase gradients are negligible $\left(P /\left(N u L e_{f}\right)<<1\right)$ and the solid conductivity is low $\left(P e_{h}>>1\right)$ the species and energy balances in the solid and fluid phases can be combined to the following pseudo-homogeneous species and energy balances.

$$
\begin{gathered}
\left(1+\frac{\epsilon_{w c}}{\varsigma}\right) \frac{\partial Y}{\partial \tau}+\frac{\partial Y}{\partial z}=-\operatorname{DaR}(Y, \theta) \\
(1+\sigma) \frac{\partial \theta}{\partial \tau}+\frac{\partial \theta}{\partial z}=\frac{1}{P e_{h}} \frac{\partial^{2} \theta}{\partial z^{2}}
\end{gathered}
$$

where $R(Y, \theta)$ is the dimensionless reaction rate as defined in the previous section.

The corresponding boundary and initial conditions are:

$$
\begin{gathered}
Y(0, \tau)=Y_{i n}(\tau) \\
\frac{1}{P e_{h}} \frac{\partial \theta(0, \tau)}{\partial z}=\theta(0, \tau)-\theta_{i n}(\tau) ; \quad \frac{\partial \theta(1, \tau)}{\partial z}=0 \\
Y(z, 0)=Y_{0}(z) ; \quad \theta(z, 0)=0
\end{gathered}
$$

Ignoring the solid conduction i.e. $\left(P e_{h} \rightarrow \infty\right)$ reduces Eqn.(27) to a first order hyperbolic 
Eqn.(31).

$$
(1+\sigma) \frac{\partial \theta}{\partial \tau}+\frac{\partial \theta}{\partial z}=0
$$

The corresponding initial and inlet conditions are

$$
\begin{gathered}
\theta(z, 0)=0 \\
\theta(0, \tau)=\theta_{\text {in }}(\tau)
\end{gathered}
$$

Deemter $[22,23]$ used these hyperbolic equations to predict the temperature and concentration fronts during coke combustion in a packed bed. We follow a similar approach here. The inlet temperature is linearly increased from an initial value to the maximum value during ramp up at constant ramp rate and it is decreased at the same ramp rate during ramp down. For convenience, we define $\widehat{\theta}=\theta T_{\text {ref }} / \alpha t_{0}$ so that the temperature during ramp up and ramp down may be expressed as

$$
\widehat{\theta_{i n}(\tau)}=\left\{\begin{array}{c}
\tau, \quad 0 \leq \tau \leq \tau_{f} \\
2 \tau_{f}-\tau, \quad \tau_{f}<\tau \leq 2 \tau_{f}
\end{array}\right\}
$$

where $\widehat{\theta_{i n}(\tau)}$ is dimensionless inlet feed temperature, $\alpha$ is the ramp rate, $t_{0}$ is the space time, $\tau_{f}$ is the dimensionless period during which the inlet feed temperature is ramped up or ramped down and $T_{\text {ref }}=T_{\text {in }}$ at time $t=0$.

Eqns.(31 -34) predict that the transient temperature during the ramp up is

$$
\widehat{\theta(z, \tau)}=\left\{\begin{array}{c}
0, \quad z>\frac{\tau}{1+\sigma} \\
\tau-(1+\sigma) z, \quad z<\frac{\tau}{1+\sigma}
\end{array}\right\}
$$

The solution during the ramp down is

$$
\widehat{\theta(z, \tau)}=\left\{\begin{array}{c}
\tau-(1+\sigma) z, \quad z>\frac{\tau-\tau_{f}}{1+\sigma} \\
2 \tau_{f}-\tau+(1+\sigma) z, \quad z<\frac{\tau-\tau_{f}}{1+\sigma}
\end{array}\right\}
$$


Fig.1 shows the transient temperature profiles for the case of $\alpha=10 \mathrm{~K} / \mathrm{min}, t_{0}=0.08 \mathrm{sec}$, $\sigma=836, \tau_{f}=9000, T_{r e f}=300 \mathrm{~K}$. The dimensionless time required for the reactor downstream to respond to a linear increase in inlet fluid temperature is $\tau_{1}=(1+\sigma)$.

According to Eqn.(31) the velocity of the thermal front depends on the heat capacity ratio of the solid to fluid and is given by

$$
v_{t}=\frac{1}{1+\sigma}
$$

Light-off curves showing exit conversion versus inlet feed temperature exhibit hysteresis due to the different temperature profiles during the ramp up and ramp down phases. We define the width of the hysteresis loop as the difference in the inlet feed temperatures corresponding to $50 \%$ conversion during the ramp up and ramp down. We conjecture that the width of the dynamic hysteresis loop is equal to the difference in the solid temperature $\left(\Delta T_{s}\right)$ between the front and back ends of the reactor. This temperature difference can be predicted from Eqns.(35) and (36).

During the ramp up period for $t>\tau_{0}(1+\sigma), \Delta T_{s}$ is

$$
\Delta T_{s}=T_{r e f}[\theta(0, t)-\theta(1, t)]=\alpha t_{0}(1+\sigma)
$$

During the ramp down period for $t>t_{\text {final }}+\tau_{0}(1+\sigma), \Delta T_{s}$ is

$$
\Delta T_{s}=T_{r e f}[\theta(0, t)-\theta(1, t)]=\alpha t_{0}(1+\sigma)
$$

Eqns.(38) and (39) predict that the same temperature difference exists between the up and downstream during the ramp up and ramp down periods. This supports our assumption that the width of hysteresis is equal to $\Delta T_{s}$ predicted by the Eqns.(38) or (39)

Converting the non-dimensional terms in Eqns.(38) or (39) to dimensional form gives an explicit expression for the width of the dynamic hysteresis in monolithic reactors:

$$
\Delta T=\alpha t_{0}\left(1+\frac{R_{\Omega_{2}} \rho_{c} c_{p c}+R_{\Omega_{s}} \rho_{s} c_{p s}}{\rho_{f} c_{p f} R_{\Omega_{1}}}\right)
$$


It mainly depends on the ramp rate, space time and heat capacity ratio. Using the definition of the thermal front velocity defined by Eqn.(37) it can be inferred that the time required for the downstream of the reactor to reach the feed temperature is $\tau_{c 1}=t_{0}(1+\sigma)$. This is one of the important characteristic time scales of the dynamic hysteresis. Another important characteristic time scale is the time required for $1^{\circ} \mathrm{C}$ increase in inlet temperature, $\tau_{c 2}=1 / \alpha$. The disparity between these two characteristic time scales is the main reason for the dynamic hysteresis when heat effects due to the reaction are negligible.

The expression for the width of hysteresis loop, Eqn.(40) is valid only in the limit of $P e_{h} \rightarrow \infty$. For finite values of $P e_{h}$, the width of the dynamic hysteresis decreases with decrease in $P e_{h}$. We present an analytical expression relating the width of hysteresis loop at any finite $P e_{h}$ to the dimensionless variance of the axial dispersion model. The expression for the width of hysteresis loop at finite $P e_{h}$ for the pseudo-homogeneous model may be approximated by Eqn.(41):

$$
\Delta T=\alpha t_{0}(1+\sigma)\left(1-g\left(P e_{h}\right)\right)
$$

where

$$
g\left(P e_{h}\right)=\frac{2}{P e_{h}}-\frac{2}{P e_{h}^{2}}\left(1-e^{-P e_{h}}\right)
$$

The width of hysteresis is 0 for pseudo-homogeneous model when $P e_{h} \rightarrow 0$ because there are no intraphase gradients in solid temperature under this limit. It should also be noted that this expression for width of hysteresis loop simplifies to pseudo-homogeneous plug flow limit when $P e_{h} \rightarrow \infty$. The function $g\left(P e_{h}\right)$ in Eqn.41 is chosen because it satisfies both the limits of $P e_{h} \rightarrow \infty$ and $P e_{h} \rightarrow 0$. We validate the analytical expression shown in Eqn.(41) by comparing it with numerically computed result. The width of hysteresis loop was numerically computed by solving the Eqns.(26-30). Fig.2 compares the numerically computed width of the hysteresis loop with the analytical expression derived using the dimensionless variance of the axial dispersion model. The slight deviation between the numerically computed results and the analytical expression is due to finite heat capacitance and the fact that variance $g\left(P e_{h}\right)$ for a step change in inlet fluid temperature differs from the transient inlet conditions being used in this study. The function $g\left(P e_{h}\right)$ is a good choice because it satisfies 
both the limiting cases and the expression for the width of the hysteresis loop compares well with numerically computed result.

\subsection{Two-phase plug flow model}

A pseudo-homogeneous model can only elucidate the impact of intraphase gradients in the solid on the dynamic hysteresis of monoliths. Interphase gradients between the solid and fluid may also cause hysteresis. This can be illustrated by investigation of a two-phase plug flow model.

Assuming a zero solid conductivity and a constant heat transfer coefficient, Eqns.(16) and (17) becomes

$$
\sigma \frac{\partial \theta_{s}}{\partial \tau}=-\frac{N u_{\Omega, \infty}}{P_{h}}\left(\theta_{s}-\theta_{m}\right)
$$

The two-phase plug flow model predicts that a constant temperature difference exists between the solid and fluid temperatures along the reactor. Using Laplace transformation to solve Eqn.43 this difference is found to be

$$
\theta_{m}(0, t)-\theta_{s}(0, t)=\frac{\alpha t_{0} P_{h} \sigma}{N u_{\Omega, \infty} T_{r e f}}\left[1-\exp \left(-N u_{\Omega, \infty} t /\left(P_{h} \sigma t_{0}\right)\right)\right]
$$

If $t \geq 3 P_{h} \sigma t_{0} / N u_{\Omega, \infty}$, the transient term may be neglected and the temperature difference between the fluid and solid at inlet is

$$
\Delta T_{i n}=T_{r e f}\left(\theta_{m}(0, t)-\theta_{s}(0, t)\right)=\alpha \tau_{0} \sigma P_{h} / N u_{\Omega, \infty} \approx \alpha \tau_{0}(1+\sigma) P_{h} / N u_{\Omega, \infty}
$$

(Since $\sigma>>1$ for most practical purposes, it is reasonable to replace $\sigma$ in Eqn.45 by $1+\sigma$ ).

Thus, the dynamic hysteresis for the two-phase plug flow model is due to both the interphase and intraphase gradients. The overall width of the hysteresis loop is the sum of the temperature difference between the reactor upstream and downstream and twice the difference between the inlet solid and fluid temperatures:

$$
\Delta T=\Delta T_{i n}+\Delta T_{s}=\alpha t_{0}(1+\sigma)\left(1+2 P_{h} / N u_{\Omega, \infty}\right)
$$


where $\Delta T$ is the overall width of hysteresis for the two-phase plug flow model.

Fig.3 describes the dependence of the width of the dynamic hysteresis loop on the transverse or interphase heat Peclet number. It shows that the width of dynamic hysteresis loop reaches the pseudo-homogeneous plug flow limit when $P_{h} \rightarrow 0$ and increases as $P_{h}$ increases. This is due to the increase in the interphase gradients between the solid and fluid temperatures with an increase in the transverse heat Peclet number.

\section{Numerical simulation of dynamic hysteresis}

We investigate the role of interphase and intraphase gradients by numerically studying the nondimensionalised two-phase model presented in section 2. In all the numerical simulations shown in this section, a single reaction $\left(\mathrm{CO}\right.$ oxidation on $\left.\mathrm{Pt} / \mathrm{Al}_{2} \mathrm{O}_{3}\right)$ is considered and heat of reaction is assumed to be zero. The latter assumption is justified only for very low concentration of $C O$ which was taken to be $100 \mathrm{ppm}$ in all the numerical simulations in this section. Numerical values of dimensionless numbers used in the simulations are reported in Table 2 . In all the simulations the feed temperature was increased from $20^{\circ} \mathrm{C}$ to $170^{\circ} \mathrm{C}$ at a ramp rate of $10^{\circ} \mathrm{C} / \mathrm{min}$ and it is ramped down to $20^{\circ} \mathrm{C}$ at the same rate.

\subsection{Effect of $P e_{h}$ on width of hysteresis}

Fig.4a shows CO conversion versus inlet fluid temperature for ramp up and ramp down periods for $P e_{h}=100$. The width of the hysteresis loop in this case is $16 \mathrm{~K}$. The analytical expression, Eqn.(40), accurately predicts this width. Poor thermal conduction results in large intraphase gradients in the solid which are the main reason for the hysteresis when the solid conductivity is negligible.

Intraphase gradients become negligible upon an increase in solid conductivity. However Fig.4b shows that a hysteresis may exist even when the intraphase gradients in the solid are negligible. Gundlapally et al. [7] showed that the transient time required for the solid temperature to attain the constant inlet fluid temperature depends on the heat capacity ratio and heat Peclet number. Interphase gradients arising due to this transient time become significant as the solid conductivity 
increases.

$T_{50, i}$ and $T_{50, e}$ indicated in fig. $4 \mathrm{~b}$ are the feed temperatures corresponding to $50 \%$ conversion during ramp up and ramp down, respectively. Fig.5 shows the solid and fluid temperature profiles during ramp up and ramp down at $T_{50, i}$ and $T_{50, e}$. They show that some interphase gradients still exist between the solid and fluid temperatures even when the gradients in the solid temperature are negligible $\left(P e_{h}=0.1\right)$. In this case, the temperature difference between the two ends of the reactor is negligible. The width of hysteresis is approximately equal to twice the difference in inlet fluid and solid temperatures. Therefore, in this limiting case (high solid conduction or low $P e_{h}$ ) the hysteresis is mainly due to interphase gradients between solid and fluid.

\subsection{Effect of $P_{h}$ on width of hysteresis}

Fig.6 shows that the width of the hysteresis loop increases with an increase in the interphase Peclet number. This increase in the width of hysteresis loop is due to the increase in interphase gradients between the solid and fluid temperature. It should be pointed that $P_{h}=P$ in this case since $L e_{f}=1$ The final conversion decreases as the interphase Peclet number increases. This is consistent with Balakotaiah et al. [24] prediction that for fully developed laminar flow, the exit conversion is inversely proportional to $P_{h}^{2 / 3}$ when $P_{h}>>1$. Fig.7 shows that there is a negligible temperature difference between the solid and fluid for small $P_{h}$ and this difference increases with increase in $P_{h}$.

\section{$5 \quad$ Steady-state and dynamic hysteresis}

In the numerical simulations shown so far the hysteresis is primarily due to the transient inlet conditions. However, the presence of non-linearity in the kinetics (e.g. exponential dependence of rate on temperature and negative order kinetics) combined with mass and thermal feedback can lead to hysteresis in steady state due to the existence of multiple steady-state solutions. Several previous studies have determined the boundary between unique and multiple solutions or the range of parameters over which steady state multiplicity can occur. This boundary locus is called the hysteresis locus in bifurcation theory. Balakotaiah [25] examined four different perturbations of 
the plug flow model to consider the effect of axial dispersion, discretization, recycle and interphase gradients and approximated the boundary between the unique and multiple solutions by analytical expressions. Here, we review and use these results. While in prior studies of steady-state behavior, the Damkohler number (or dimensionless residence time) is taken as the bifurcation variable, in the analysis of after-treatment systems the fluid inlet temperature is the most appropriate bifurcation variable.

For a first-order reaction, the expression for hysteresis locus of the pseudo-homogeneous axial dispersion model for large $P e_{h}$ values is [25]

$$
\begin{gathered}
\frac{2}{P e_{h}}=B e^{(2-B)} ; \quad D a=k\left(T_{i n}\right) t_{0}=\frac{1}{B} \\
B=\frac{E}{R T_{i n}} \frac{\Delta T_{a d}}{T_{i n}}
\end{gathered}
$$

When $1<<P e_{h}<2 \exp (B-2) / B$, the ignition and extinction loci of the axial dispersion model are

$$
\begin{gathered}
(B D a)_{i g}=1 \\
\left(\frac{D a}{P e_{h}}\right)_{e x t}=(B-1) e^{(1-B)}
\end{gathered}
$$

Similarly when $P e_{h}<<1$, the ignition and extinction loci are given by

$$
\begin{gathered}
(D a)_{i g}=e^{-1} / B \\
(D a)_{e x t}=(B-1) e^{1-B}
\end{gathered}
$$

Eqs.(47) and (48) may be used to calculate the species concentration above which steady-state hysteresis occurs. For species concentration above this value eqs.(49)-(52) may be used to calculate the range of inlet temperatures (for a fixed residence time $t_{0}$ ) or residence times (for a fixed inlet 
temperature) over which multiple solutions exist.

When interphase heat and mass transfer are introduced into the species and energy balances, hysteresis locus is predicted by the expression for two-phase plug flow model which for small values of $P_{h}$ is $[25]$

$$
P_{h}=(B-1) e^{(2-B)}
$$

For $P_{h}>(B-1) e^{(2-B)}$, the ignition locus for the two-phase model may be approximated by

$$
\frac{e B D a P_{h}}{N u_{\Omega, \infty}}>1
$$

No analytical expression exists in the literature for predicting the extinction locus of the two-phase model. For the model with both axial dispersion and interphase gradients, an analytical expression for the hysteresis locus can be obtained by replacing $P e$ in Eqn.47 by the effective Peclet number, $P e_{h, \text { eff }}$. Therefore, the expression for hysteresis locus for the model with both axial dispersion and interphase gradients may be approximated by

$$
\frac{2}{P e_{h, e f f}}=B e^{(2-B)},
$$

where

$$
\frac{1}{P e_{h, e f f}}=\frac{1}{P e_{h}}+\frac{P}{N u_{\Omega \infty} L e_{f}}
$$

Steady state simulations for ethane oxidation were performed to validate these analytical expressions. Fig. 8 shows the steady state bifurcation diagram for ethane oxidation on $\mathrm{Pt} / \mathrm{Al}_{2} \mathrm{O}_{3}$ which is computed by numerically solving the dimensional steady-state two-phase model presented in section 2. The values of the constant parameters and temperature dependent parameters used in all the numerical simulations of the dimensional two-phase model are listed in Table 3 and Table 4, respectively. It shows that steady state multiplicity exists for a feed with 7000ppm ethane whereas no steady state multiplicity exists for a feed of 4000ppm of ethane. A feed concentration of 5500ppm $\left(\Delta T_{a d}=310 K\right)$ of ethane is required to get steady-state multiplicity. The analytical expression, 
Eqn.47, predicts that $\Delta T_{a d}$ required for steady-state multiplicity is $285 K$ for $P e_{h}=100$. This confirms that the analytical expression in Eqn.47 closely predicts the boundary of multiple solutions. For 7000ppm of ethane, both ignition and extinction exist. The analytical expression, Eqs.(49) and (50) predict that the ignition and extinction temperatures are $600 \mathrm{~K}$ and $450 \mathrm{~K}$, respectively (The width of the steady-state hysteresis is $150 \mathrm{~K})$. These values compare well with numerically predicted values $(635 \mathrm{~K}$ and $460 \mathrm{~K})$ or the width of hysteresis which is about $175 \mathrm{~K}$. This supports our statement that the analytical expressions, Eqs.(49) and (50) are rough estimates of the ignition and extinction temperatures and become more accurate for large values of $B$. In the subsequent analysis, we determine the steady state hysteresis behavior of $C O$ oxidation by ramping up and down the fluid feed temperature at a very low ramp rate. The simulations that show light-off curves during ramp up and down phases closely resemble the steady state bifurcation diagrams when the ramp rate of feed temperature is $1 \mathrm{~K} / \mathrm{min}$.

Adiabatic temperature rise depends on the heat of the reaction, molar heat capacity and inlet concentration of limiting reactant. Earlier studies determined $\Delta T_{a d}$ required for every $P e_{h}$ to attain steady state multiplicity for various limiting models. Fig.9 shows the steady-state light-off curves for $500 \mathrm{ppm}\left(\Delta T_{a d}=4.7 \mathrm{~K}\right), 2 \%\left(\Delta T_{a d}=188 \mathrm{~K}\right)$ and $3 \%\left(\Delta T_{a d}=282 \mathrm{~K}\right)$ of $C O$ in the feed. These curves are obtained using a very low ramp rate of $1 \mathrm{~K} / \mathrm{min}$ so that ignition and extinction are very close to the steady state values. For a feed of $500 \mathrm{ppm}$ steady-state multiplicity does not exist. On the other hand for a feed of $2 \%$ and $3 \%$ CO steady-state multiplicity exists. Steady-state multiplicity region expands with increase in feed concentration of $C O$. Steady-state multiplicity exists if $\Delta T_{a d}$ exceeds $\Delta T_{a d, c}$ (critical adiabatic temperature defined as minimum $\Delta T_{a d}$ required to attain steady state multiplicity). Gu and Balakotaiah [26] showed how adiabatic temperature rise required for steady-state multiplicity changes with heat Peclet number for both linear kinetics and LangmuirHinshelwood kinetics.

\section{Impact of $\mathrm{Pe}_{h}$, ramp rate and residence time on steady-state and dy-} namic hysteresis behavior

Axial Peclet heat number and transverse Peclet heat number affect the existence of steady state multiplicity. The intraphase gradients in the solid and interphase gradients between solid and fluid can be quantified by these dimensionless numbers. Fig.10 shows that the width of the hysteresis loop 
decreases as $P e_{h}$ increases. The interphase heat Peclet is taken to be 0.03 . In general, the width of the hysteresis loop decreases upon a decrease in $P_{h}$.

The rate at which fluid feed temperature is ramped up or down has significant impact on the dynamic hysteresis. Fig.11 shows that the hysteresis region expands with an increase in the ramp

rate. While the hysteresis for a ramp rate of $1 \mathrm{~K} / \mathrm{min}$ is mainly due to steady state multiplicity, hysteresis under a ramp rate of $10 \mathrm{~K} / \mathrm{min}$ is due to the combined effect of steady state multiplicity and feed ramp up rate. Fig.11 shows that the ignition temperature increases and the extinction temperature decreases with an increase in the ramp rate. This expansion in the multiplicity region is primarily due to the transient change in feed temperature that causes a delay in heat transport along the monolith.

Residence time or space velocity has significant impact on the extent of reaction. Fig.12 shows the conversion during ramp up and down for two different residence times. It shows that both the ignition and extinction temperatures increase upon a decrease in residence time. In addition the final conversion decreases upon a decrease in residence time.

\section{Hysteresis during co-oxidation of a $\mathrm{CO}$ and $\mathrm{C}_{2} \mathrm{H}_{6}$ mixture}

\section{on $\mathrm{Pt} / \mathrm{Al}_{2} \mathrm{O}_{3}$}

It is of interest to predict how the ignition of one species in a mixture affects that of others. We study here the dynamic hysteresis behavior during co-oxidation of $\mathrm{CO}$ and $\mathrm{C}_{2} \mathrm{H}_{6}$ on $\mathrm{Pt} / \mathrm{Al}_{2} \mathrm{O}_{3}$ using the dimensional form of the two-phase model presented in section 2 .

Fig.13 shows the hysteresis behavior during ramp up and ramp down of pure $C O$ oxidation and of pure $\mathrm{C}_{2} \mathrm{H}_{6}$ oxidation. It shows that light-off temperature (feed temperature corresponding to $50 \%$ conversion) of $1 \% \mathrm{CO}$ is $473 \mathrm{~K}$ whereas light-off temperature of $500 \mathrm{ppm} \mathrm{C}_{2} \mathrm{H}_{6}$ is $723 \mathrm{~K}$. Ignition temperature is the temperature corresponding to $50 \%$ conversion when steady state hysteresis does not exist. Thus, the co-oxidation of $\mathrm{CO}+\mathrm{C}_{2} \mathrm{H}_{6}$ represents a system in which the ignition temperatures of each of the components are well separated (In this case the difference between light-off temperatures of $\mathrm{CO}$ and $\mathrm{C}_{2} \mathrm{H}_{6}$ is $\left.250 \mathrm{~K}\right)$. It is useful to use a species with a low ignition temperature to ignite the 
one with a high ignition temperature. In this example, $C O$ is the species with a low ignition temperature and $\mathrm{C}_{2} \mathrm{H}_{6}$ is the one with a high ignition temperature. Although, this work considers only two component mixture, this concept can be extended to a multi reactants mixture and can be applied in many after-treatment systems in which several species need to be ignited. One example is a Diesel Oxidation Catalyst (DOC) used to convert $\mathrm{HCs}$ and $\mathrm{CO}$ into $\mathrm{CO}_{2}$ and $\mathrm{H}_{2} \mathrm{O}$. The exotherm generated by the oxidation of the low temperature ignited species can be used to ignite the species with the high ignition temperature. The adiabatic temperature rise for a feed containing $C O$ and $\mathrm{C}_{2} \mathrm{H}_{6}$ is

$$
\Delta T_{a d}=\frac{\left(-\Delta H_{R, C O}\right) Y_{C O, i n}}{\left\langle C_{P}\right\rangle}+\frac{\left(-\Delta H_{R, C_{2} H_{6}}\right) Y_{C_{2} H_{6}, i n}}{\left\langle C_{P}\right\rangle}=9407 Y_{C O, i n}+51858 Y_{C_{2} H_{6}, i n}
$$

Fig.14 shows $\mathrm{C}_{2} \mathrm{H}_{6}$ light-off curves during ramp up for mixture with different $C O$ feed compositions. The light-off temperature of pure $\mathrm{C}_{2} \mathrm{H}_{6}$ is $723 \mathrm{~K}$. The oxidation of $C O$ present in the feed increases the catalyst temperature. This solid temperature rise reduces the feed temperature at which light-off of $\mathrm{C}_{2} \mathrm{H}_{6}$ occurs. Fig. 14 shows that light-off temperature of $\mathrm{C}_{2} \mathrm{H}_{6}$ is reduced by $80 \mathrm{~K}$ for every $1 \% C O$ in the feed. The presence of $C O$ in the feed enhances the light-off performance of $\mathrm{C}_{2} \mathrm{H}_{6}$. Table 5 reports the light-off temperatures during ramp up and ramp down for various feed compositions of $\mathrm{CO}$ and $\mathrm{C}_{2} \mathrm{H}_{6}$. It can be observed from Table 5 that light-off temperature of $\mathrm{C}_{2} H_{6}$ decreases by less than $80 \mathrm{~K}(563 K-503 K)$ when the feed $C O$ concentration in the mixture is increased from 2 to $3 \%$. This is because $\mathrm{C}_{2} \mathrm{H}_{6}$ ignites only after entire $\mathrm{CO}$ is converted to $\mathrm{CO}_{2}$ and $C O$ ignites at $493 K$.

Fig.15a shows the light-off curves of a mixture of $3 \% \mathrm{CO}$ and $500 \mathrm{ppm} \mathrm{C}_{2} \mathrm{H}_{6}$. In this case, the ignition temperatures of $\mathrm{CO}$ and $\mathrm{C}_{2} \mathrm{H}_{6}$ are rather close. A $\mathrm{CO}$ feed concentration of $3 \%$ is required to ignite the $500 \mathrm{ppm}$ of ethane almost simultaneously. The concentration of $C O$ required for a simultaneous ignition decreases as the feed concentration of $C_{2} H_{6}$ increases. Fig.15b shows the dependence of solid exit temperature on feed temperature. The extinction temperatures is much lower $(243 \mathrm{~K})$ for the case of $3 \%$ CO in the feed. The solid remains in the ignited branch longer for higher concentrations of $C O$ in the feed due to the high exotherm generated by $C O$ oxidation.

Fig.16a shows $\mathrm{C}_{2} \mathrm{H}_{6}$ light-off curves for mixture of $1 \% \mathrm{CO}$ with different feed concentration of 
$\mathrm{C}_{2} \mathrm{H}_{6}$. It shows that light-off temperature of $\mathrm{C}_{2} \mathrm{H}_{6}$ is slightly decreased with an increase in feed $\mathrm{C}_{2} \mathrm{H}_{6}$ concentration because for positive order kinetics light-off temperature decreases with increase in feed concentration. The bifurcation diagrams showing the dependence of the difference of solid exit temperature and feed temperatures on fluid inlet temperature provide useful insight on ignition of $\mathrm{CO}+\mathrm{C}_{2} \mathrm{H}_{6}$ mixtures. Fig.16b shows how the difference of solid exit temperature and feed temperature changes with ramped feed temperature for a feed with $1 \% \mathrm{CO}$ and different mole fractions of $\mathrm{C}_{2} \mathrm{H}_{6}$. While the jump in the solid exit temperature corresponding to $\mathrm{CO}$ ignition is clearly evident, the temperature jump corresponding to the oxidation of $500 \mathrm{ppm}$ of ethane is not clearly observed due to its low adiabatic temperature rise. Similar bifurcation diagram with higher feed concentrations of $\mathrm{C}_{2} \mathrm{H}_{6}$ show the separate ignitions of $\mathrm{CO}$ and $\mathrm{C}_{2} \mathrm{H}_{6}$. Here we refer to a jump in solid exit temperature as ignition and Fig.16b shows two separate ignitions. The first ignition corresponds to $C O$ oxidation and the second to $\mathrm{C}_{2} \mathrm{H}_{6}$ oxidation. Two separate ignitions exist for lower feed $C O$ concentrations and this ignition behavior switches to simultaneous ignition when the feed $C O$ concentration is sufficiently high.

In the previous section, the impact of ramp rate on ignition and extinction behavior of $C O$ oxidation is studied. In this section we study the impact of ramp rate on ignition and extinction behavior of a mixture containing both $\mathrm{CO}$ and $\mathrm{C}_{2} \mathrm{H}_{6}$. Fig.17 shows that the ignition temperature increases and the extinction temperature decreases with an increase in ramp rate. The time required for the downstream of the reactor to respond to the changes in feed temperature increases as the ramp rate increases and this delays the ignition. Fig.17 shows that for a ramp rate of $10 \mathrm{~K} / \mathrm{min}$, the ignition of $\mathrm{CO}$ and $\mathrm{C}_{2} \mathrm{H}_{6}$ occurs at very close but not at the same temperatures. However in the case of $1 \mathrm{~K} / \mathrm{min}$ ignition happens almost simultaneously. Thus, high concentration of $C O$ at very low ramp rate can facilitate simultaneous ignition of $C O$ and $C_{2} H_{6}$ in a feed containing both $C O$ and $\mathrm{C}_{2} \mathrm{H}_{6}$.

\section{$7 \quad$ Summary and discussion}

The main contributions of this work are: (i) a detailed analysis and prediction of the impact of ramp rate, thermal properties and operating conditions on the width of the dynamic hysteresis loop 
when heat generated by the reaction is negligible, (ii) analysis of the impact of inter and intra-phase gradients on dynamic hysteresis, (iii) analysis and simulation of the combined effect of steady state and dynamic hysteresis behavior and, (iv) analysis of light-off behavior during co-oxidation of $C O$ and $\mathrm{C}_{2} \mathrm{H}_{6}$ on $\mathrm{Pt} / \mathrm{Al}_{2} \mathrm{O}_{3}$.

We presented analytical predictions of the width of the dynamic hysteresis loop using simplified models, which capture the essential behavioral features of the full reactor model. To derive these analytical expressions we assumed that the width of the hysteresis loop is the sum of the difference in solid temperatures between the up and downstream of the reactor and the difference in the solid and fluid temperatures at the upstream of the reactor. Numerical simulations validate this assumption and the analytical expressions derived using the limiting models.

The effect of solid conductivity on the width of hysteresis loop was studied. We found that dynamic hysteresis is due to intraphase gradients in the solid temperature at large $P e_{h}$ (poor thermal feedback) and due to interphase gradients between the solid and fluid temperature at small $P e_{h}$. Numerical simulations showed that as $P_{h}$ increases the heat transfer between the solid and fluid becomes the limiting process. This increases the interphase gradients between the solid and fluid phases. Dynamic hysteresis is due to interphase gradients at low $P e_{h, e f f}$ (at low $P e_{h}$ and high $P_{h}$ ) and intraphase gradients at high $P e_{h, e f f}$.

Our study reveals that hysteresis can occur even when the reaction heat is negligible. The primary reason for this dynamic hysteresis is the delay in the response of the solid temperature to the changes in the inlet feed temperature. When the heat generated by a reaction is not negligible, hysteresis is generated due to a combined effect of thermokinetic multiplicity and ramp up and down of the feed temperature. Steady-state hysteresis at very low ramp rates is mainly due to steady state multiplicity. At high ramp rates hysteresis is due to both steady-state multiplicity and transient feed temperature ramp.

Temperature programmed modelling studies provide useful insight on dynamic hysteresis during co-oxidation of $\mathrm{CO}+\mathrm{C}_{2} \mathrm{H}_{6}$ on $\mathrm{Pt} / \mathrm{Al}_{2} \mathrm{O}_{3}$. This study elucidates the the ignition and extinction behavior of the system in which ignition temperatures of two components are much different from each other. The heat generated by the oxidation of the one of the reactants reduces the light-off temperatures of the other reactants. This heat which increases with increase in feed mole fractions 
of the more active species raises the solid temperatures. Higher solid temperatures may deactivate the catalyst. Therefore, it is important to use a thermally stable catalyst to take the advantage of the exothermicity of species that ignite at low temperature.

In this work we demonstrated the impact of feed composition on hysteresis in monolith reactors during co-oxidation of $\mathrm{CO}$ and $\mathrm{C}_{2} \mathrm{H}_{6}$. A similar approach may be used to study the dynamic hysteresis behavior during co-oxidation of $\mathrm{CO}, \mathrm{H}_{2}$ and other $\mathrm{HCs}$. An analysis of steady-state and dynamic hysteresis for system with $C O$ and different $H C s$ will be pursued in future work.

Acknowledgements : This study was funded by grants from the U.S. DOE National Energy Technology Laboratory as part of the Vehicles Technologies Program DOE-NETL (DE-EE0000205) and National Science Foundation CBET 1258688.

\section{Nomenclature}

Roman letters

$B=$ Zeldovich number(dimensionless adiabatic temperature rise)

$C_{0}=$ total concentration in gas phase

$c_{p c}=$ washcoat heat capacity

$c_{p f}=$ specific gas heat capacity in fluid phase

$c_{p s}=$ support heat capacity

$c_{p w}=$ effective wall heat capacity

$D a=$ Damkohler number

$D_{e}=$ effective diffusivity in the washocoat

$D_{f}=$ diffusivity in fluid phase

$E_{i}=$ activation energy for oxidation of species i

$h\left(z^{\prime}\right)=$ heat transfer coefficient

$k_{i}=$ rate constant for oxidation of species $\mathrm{i}$

$k_{m e}\left(z^{\prime}\right)=$ external mass transfer coefficient

$k_{m i}\left(z^{\prime}\right)=$ internal mass transfer coefficient

$k_{m o}\left(z^{\prime}\right)=$ overall mass transfer coefficient

$k_{w}=$ effective wall thermal conductivity 
$L=$ length of the channel

$L e_{f}=$ Lewis number

$N=$ number of reactions

$N u_{\Omega}(z)=$ position dependent Nusselt number

$N u_{\Omega, \infty}=$ asymptotic Nusselt number

$P=$ transverse Peclet number

$P_{h}=$ transverse heat Peclet number

$P e_{h}=$ heat Peclet number

$P e_{h, e f f}=$ Effective heat Peclet number

$R_{g}=$ universal gas constant

$R_{i}=$ volumetric rate of reaction $\mathrm{i}$

$R_{\Omega_{1}}=$ hydraulic radius

$R_{\Omega_{2}}=$ effective transverse diffusion length in washcoat

$R_{\Omega_{s}}=$ effective support thickness

$R_{\Omega_{w}}=$ effective solid phase thickness

$S h_{e}\left(z^{\prime}\right)=$ position dependent external Sherwood number

$S h_{i, \infty}=$ asymptotic internal Sherwood number

$t=$ time

$t_{0}=$ residence time

$T_{f}=$ fluid temperature

$T_{s}=$ solid temperature

$<u>=$ average velocity

$Y_{f m}=$ cup-mixing mole fraction of fluid phase

$<Y_{w c}>=$ average mole fraction in washcoat

$z=$ dimensionless spatial co-ordinate

$z^{\prime}=$ spatial co-ordinate along the length of channel

Greek letters

$\Delta H=$ heat of reaction

$\Delta T_{a d}=$ adiabatic temperature rise 
$\Delta T_{\text {in }}=$ difference between solid and fluid temperatures at inlet $\Delta T_{s}=$ temperature difference between two ends

$\alpha=$ ramp rate

$\beta=$ dimensionless adiabatic temperature rise

$\epsilon_{w c}=$ washcoat porosity

$\theta_{m}=$ dimensionless fluid temperature

$\theta_{s}=$ dimensionless solid temperature

$\nu_{t}=$ thermal front velocity

$\rho_{c}=$ washcoat density

$\rho_{f}=$ gas density

$\rho_{s}=$ support density

$\rho_{w}=$ solid phase density

$\sigma=$ heat capacity ratio

$\varsigma=$ ratio of hydraulic radii

$\tau=$ dimensionless time

$\tau_{f}=$ dimensionless time for which temperature is ramped up or down

$v_{i j}=$ stoichiometric coefficients of species $\mathrm{j}$ in reaction $\mathrm{i}$ 


\section{References}

[1] V. Balakotaiah and D. Luss, Structure of the steady-state solutions of lumped-parameter chemically reacting systems. Chemical Engineering Science 37.11 (1982) 1611-1623.

[2] V. Balakotaiah and D. Luss, Multiplicity features of reacting systems: dependence of the steadystates of a CSTR on the residence time. Chemical Engineering Science 38.10 (1983) 1709-1721

[3] V. Balakotaiah and D. Luss, Global analysis of the multiplicity features of multi-reaction lumped-parameter systems, Chemical Engineering Science, 39(5) (1984) 865-881.

[4] M.P. Harold, M. Sheintuch and D. Luss, Analysis and modeling of multiplicity features. 1. Nonisothermal experiments, Industrial \& engineering chemistry research, 26(4) (1987) 786-794.

[5] M.P. Harold, M. Sheintuch and D. Luss, Analysis and modeling of multiplicity features. 2. Isothermal experiments, Industrial \& engineering chemistry research, 26(4) (1987) 794-804.

[6] K. Ramanathan, V. Balakotaiah and D.H. West, Light-off criterion and transient analysis of catalytic monoliths, Chemical Engineering Science, 58(8) (2003) 1381-1405.

[7] S.R. Gundlapally and V. Balakotaiah, Analysis of the effect of substrate material on the steadystate and transient performance of monolith reactors, Chemical Engineering Science 92 (2013) $198-210$.

[8] S. Salomons, R.E. Hayes, M. Votsmeier, A. Drochner, H. Vogel, S. Malmberg and J. Gieshoff, On the use of mechanistic CO oxidation models with a platinum monolith catalyst, Applied Catalysis B: Environmental, 70(1) (2007) 305-313.

[9] A. Abedi, R. Hayes, M. Votsmeier and W.S. Epling, Inverse Hysteresis Phenomena During CO and $\mathrm{C}_{3} \mathrm{H}_{6}$ Oxidation over a Pt/ $\mathrm{Al}_{2} \mathrm{O}_{3}$ Catalyst, Catalysis letters 142(8) (2012) 930-935.

[10] W. Hauptmann, M. Votsmeier, J. Gieshoff, A.Drochner and H.Vogel, Inverse hysteresis during the NO oxidation on Pt under lean conditions, Catalysis letters 142.8 (2012) 930-935. 
[11] R. Raj, M. P. Harold and V.Balakotaiah, Steady-state and dynamic hysteresis effects during lean co-oxidation of $\mathrm{CO}$ and $\mathrm{C}_{3} \mathrm{H}_{6}$ over $\mathrm{Pt} / \mathrm{Al} 2 \mathrm{O} 3$ monolithic catalyst, Chemical Engineering Journal 281 (2015) 322-333.

[12] M. Sun, E.B. Croiset, R. R. Hudgins, P.L. Silveston and M. Menzinger, Steady-state multiplicity and superadiabatic extinction waves in the oxidation of $\mathrm{CO} / \mathrm{H} 2$ mixtures over a $\mathrm{Pt} / \mathrm{Al}_{2} \mathrm{O}_{3}$-coated monolith. Industrial \& engineering chemistry research, 42(1) (2003) 37-45.

[13] D. Bhatia, M.P. Harold and V. Balakotaiah, Kinetic and bifurcation analysis of the cooxidation of $\mathrm{CO}$ and $\mathrm{H}_{2}$ in catalytic monolith reactors, Chemical Engineering Science 64.7 (2009) 15441558

[14] P.A. Carlsson and M. Skoglundh, Low-temperature oxidation of carbon monoxide and methane over alumina and ceria supported platinum catalysts, Applied Catalysis B: Environmental 101.3 (2011) 669-675.

[15] S.Y. Joshi, M.P. Harold and V. Balakotaiah, Low-dimensional models for real time simulations of catalytic monoliths, AIChE journal, 55(7) (2009) 1771-1783.

[16] S.Y. Joshi, M.P. Harold and V. Balakotaiah, Overall mass transfer coefficients and controlling regimes in catalytic monoliths, Chemical Engineering Science 65.5 (2010) 1729-1747.

[17] S.Y. Joshi, M.P. Harold and V. Balakotaiah, On the use of internal mass transfer coefficients in modeling of diffusion and reaction in catalytic monoliths, Chemical Engineering Science 64(23) (2009) 4976-4991.

[18] M. Bhattacharya, M.P. Harold and V. Balakotaiah, Shape normalization for catalytic monoliths, Chemical engineering science 59.18 (2004) 3737-3766.

[19] T.F. Garetto, E. Rincón and C. R. Apesteguia, The origin of the enhanced activity of Pt/zeolites for combustion of C2-C4 alkanes, Applied Catalysis B: Environmental 73.1 (2007) 65-72

[20] N. Gupta and V. Balakotaiah, Heat and mass transfer coefficients in catalytic monoliths, Chemical Engineering Science, 56(16) (2001) 4771-4786. 
[21] S.M. Dommeti, V. Balakotaiah and D.H. West, Analytical criteria for validity of pseudohomogeneous models of packed-bed catalytic reactors, Industrial \& engineering chemistry research, 38(3) (1999) 767-777

[22] J.J.V. Deemter, Heat and Mass Transport in a Fixed Catalys Bed during Regeneration, Industrial \& Engineering Chemistry 45.6 (1953) 1227-1233.

[23] J.J.V. Deemter, Heat and mass transport in a fixed catalyst bed during regeneration, Industrial \& Engineering Chemistry 46.11 (1954) 2300-2302.

[24] V. Balakotaiah, N. Gupta and D. H. West, A simplified model for analyzing catalytic reactions in short monoliths, Chemical Engineering Science 55.22 (2000) 5367-5383.

[25] V. Balakotaiah, Structural stability of nonlinear convection-reaction models, Chemical Engineering Education 30 (1996) 234-239.

[26] T. Gu and V. Balakotaiah, Impact of heat and mass dispersion and thermal effects on the scale-up of monolith reactors. Chemical Engineering Journal, 284 (2016) 513-535. 
Table 1: List of kinetic parameters used in calculations

\begin{tabular}{|c|c|c|}
\hline Parameter & Value & Units \\
\hline$A_{C O}$ & $1.28 * 10^{21}$ & moles $\mathrm{m}^{-3} \mathrm{~s}^{-1}$ \\
\hline$A_{I C O}$ & 88.59 & - \\
\hline$A_{C_{2} H_{6}}$ & $0.85 * 10^{10}$ & moles $\mathrm{m}^{-3} \mathrm{~s}^{-1}$ \\
\hline$\frac{E_{C O}}{R_{g}}$ & 14421.5 & $K$ \\
\hline$\frac{-\Delta H_{I C O}}{R_{g}}$ & 1161.9 & $K$ \\
\hline$\frac{E_{C_{2} H_{6}}}{R_{g}}$ & 9262 & $K$ \\
\hline
\end{tabular}

Table 2: List of dimensionless numbers used in analysis of dynamic hysteresis

\begin{tabular}{|c|c|}
\hline Parameter & Value \\
\hline$P_{h}$ & 0.03 \\
\hline$\sigma$ & 1200,800 \\
\hline$\varsigma$ & 10.5 \\
\hline$L e_{f}$ & 1.0 \\
\hline$S h$ & 4.364 \\
\hline$N u$ & 4.364 \\
\hline$P e_{h}$ & $0.1-100$ \\
\hline
\end{tabular}


Table 3: List of constant parameters used in simulations

\begin{tabular}{|c|c|c|}
\hline Parameter & Value & Units \\
\hline$R_{\Omega_{1}}$ & 262 & $\mu \mathrm{m}$ \\
\hline$R_{\Omega_{2}}$ & 25 & $\mu \mathrm{m}$ \\
\hline$L$ & 6.35 & $\mathrm{~cm}$ \\
\hline$R_{\Omega_{w}}$ & 107.5 & $\mu \mathrm{m}$ \\
\hline$\rho_{f}$ & 0.89 & $\mathrm{~kg} / \mathrm{m}^{3}$ \\
\hline$c_{p f}$ & 1014 & $\mathrm{~J} / \mathrm{kg} / \mathrm{K}$ \\
\hline$k_{f}$ & 0.03 & $\mathrm{~W} / \mathrm{m} / \mathrm{K}$ \\
\hline$\rho_{w}$ & 2000 & $\mathrm{~kg} / \mathrm{m}^{3}$ \\
\hline$c_{p w}$ & 1000 & $\mathrm{~J} / \mathrm{kg} / \mathrm{K}$ \\
\hline$k_{w}$ & 1.5 & $\mathrm{~W} / \mathrm{m} / \mathrm{K}$ \\
\hline$\Delta H_{C O}$ & -283 & $\mathrm{~kJ} / \mathrm{mol}$ \\
\hline$\Delta H_{C_{2} H_{6}}$ & -1560 & $\mathrm{~kJ} / \mathrm{mol}$ \\
\hline
\end{tabular}


Table 4: Temperature dependent parameters used in the simulations

\begin{tabular}{|c|c|c|}
\hline Parameter & Expression & Units \\
\hline$D_{f, C O}$ & $9.58 * 10^{-10} * T_{f}^{1.75}$ & $\mathrm{~m}^{2} / \mathrm{s}$ \\
\hline$D_{f, C_{2} H_{6}}$ & $3 * 10^{-10} * T_{f}^{1.835}$ & $\mathrm{~m}^{2} / \mathrm{s}$ \\
\hline$D_{f, O_{2}}$ & $1.2 * 10^{-9} * T_{f}^{1.7019}$ & $\mathrm{~m}^{2} / \mathrm{s}$ \\
\hline$<u>$ & $0.64 * \frac{T_{f}}{298.15}$ & $\mathrm{~m} / \mathrm{s}$ \\
\hline
\end{tabular}


Table 5: Ignition and extinction temperatures

\begin{tabular}{|c|c|c|c|c|c|}
\hline $\mathrm{CO}(\%)$ & $C_{2} \mathrm{H}_{6}(\%)$ & $T_{50, i}(\mathrm{CO})$ & $T_{50, e}(\mathrm{CO})$ & $T_{50, i}\left(\mathrm{C}_{2} \mathrm{H}_{6}\right)$ & $T_{50, e}\left(\mathrm{C}_{2} \mathrm{H}_{6}\right)$ \\
\hline 1 & 0 & $478 K$ & $383 K$ & - & - \\
\hline 0 & 0.05 & - & - & $723 K$ & $703 K$ \\
\hline 1 & 0.05 & $478 K$ & $383 K$ & $643 K$ & $623 K$ \\
\hline 2 & 0.05 & $488 K$ & $313 K$ & $563 K$ & $543 K$ \\
\hline 3 & 0.05 & $493 K$ & $243 K$ & $503 K$ & $463 K$ \\
\hline 1 & 0.1 & $478 K$ & $383 K$ & $633 K$ & $613 K$ \\
\hline 1 & 0.2 & $478 K$ & $383 K$ & $623 K$ & $593 K$ \\
\hline
\end{tabular}




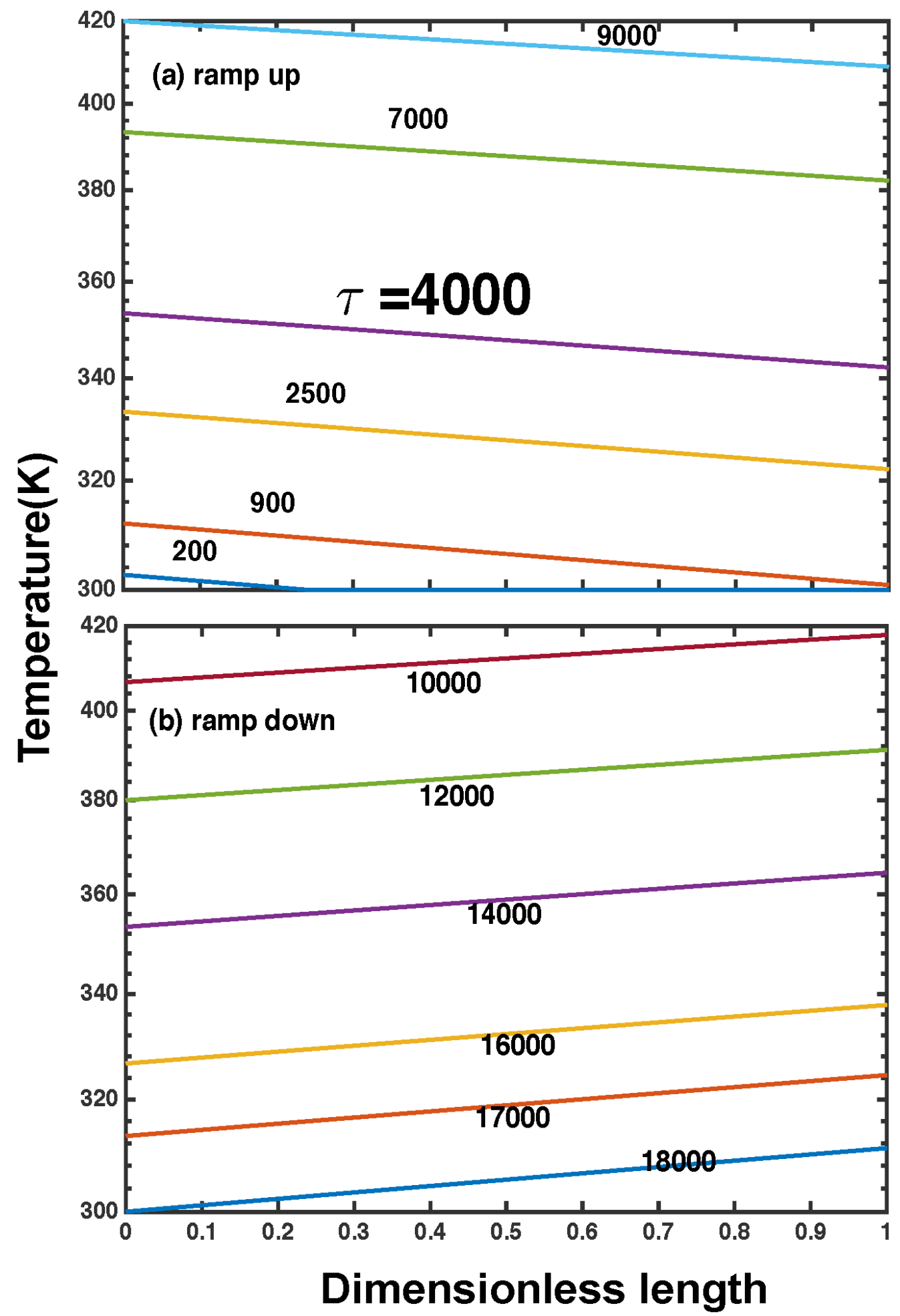

Figure 1: Transient reactor temperature profiles during ramp up and ramp down. ( $\sigma=836 ; t_{0}=$ $0.08 \mathrm{~s} ; \mathrm{ramp}$ rate $=10 \mathrm{~K} / \mathrm{min})$ 


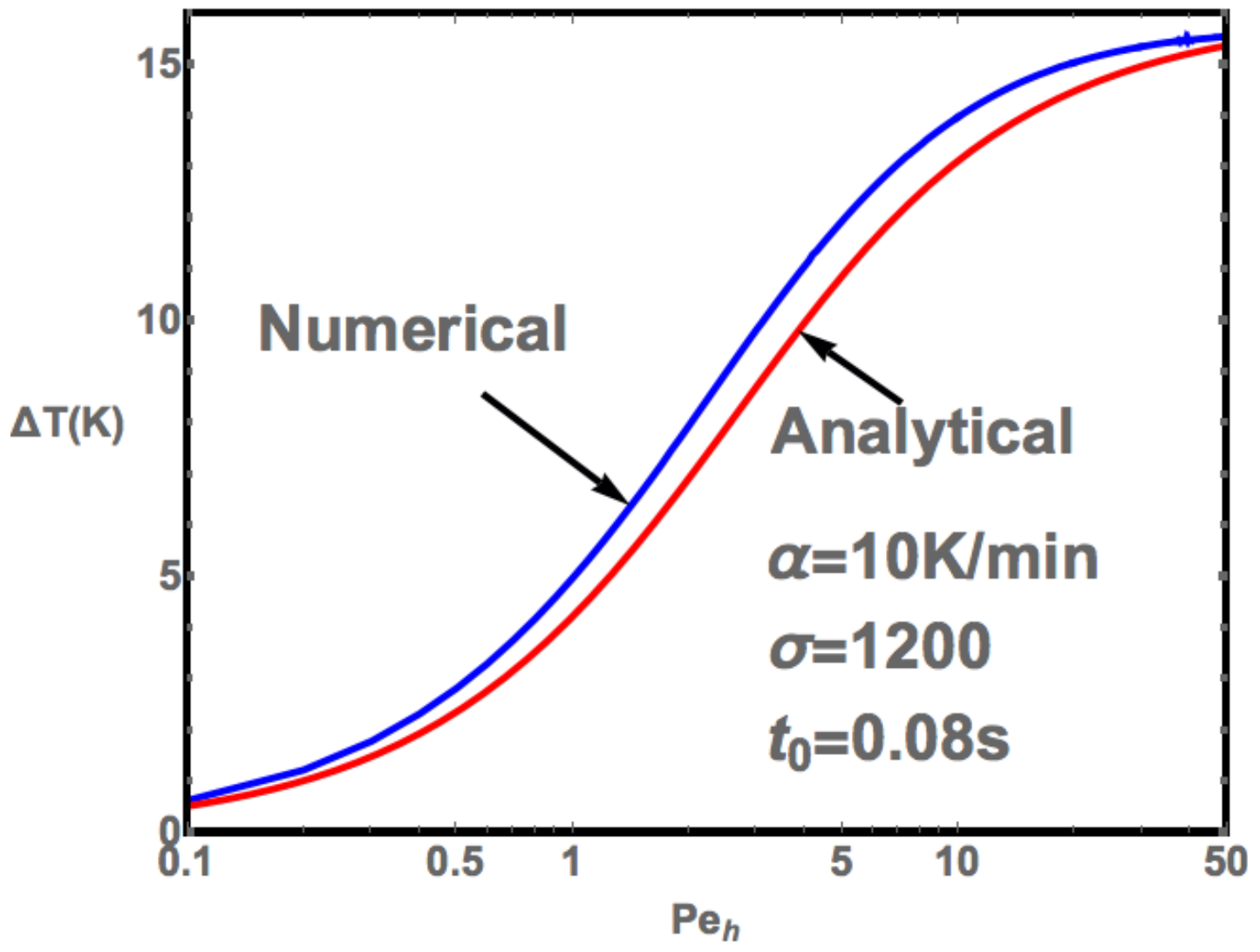

Figure 2: Comparison of numerical and analytical predictions of the width of hysteresis loop $\Delta T$ with heat Peclet number, $P e_{h}$ for inlet $C O=100 \mathrm{ppm}$. 


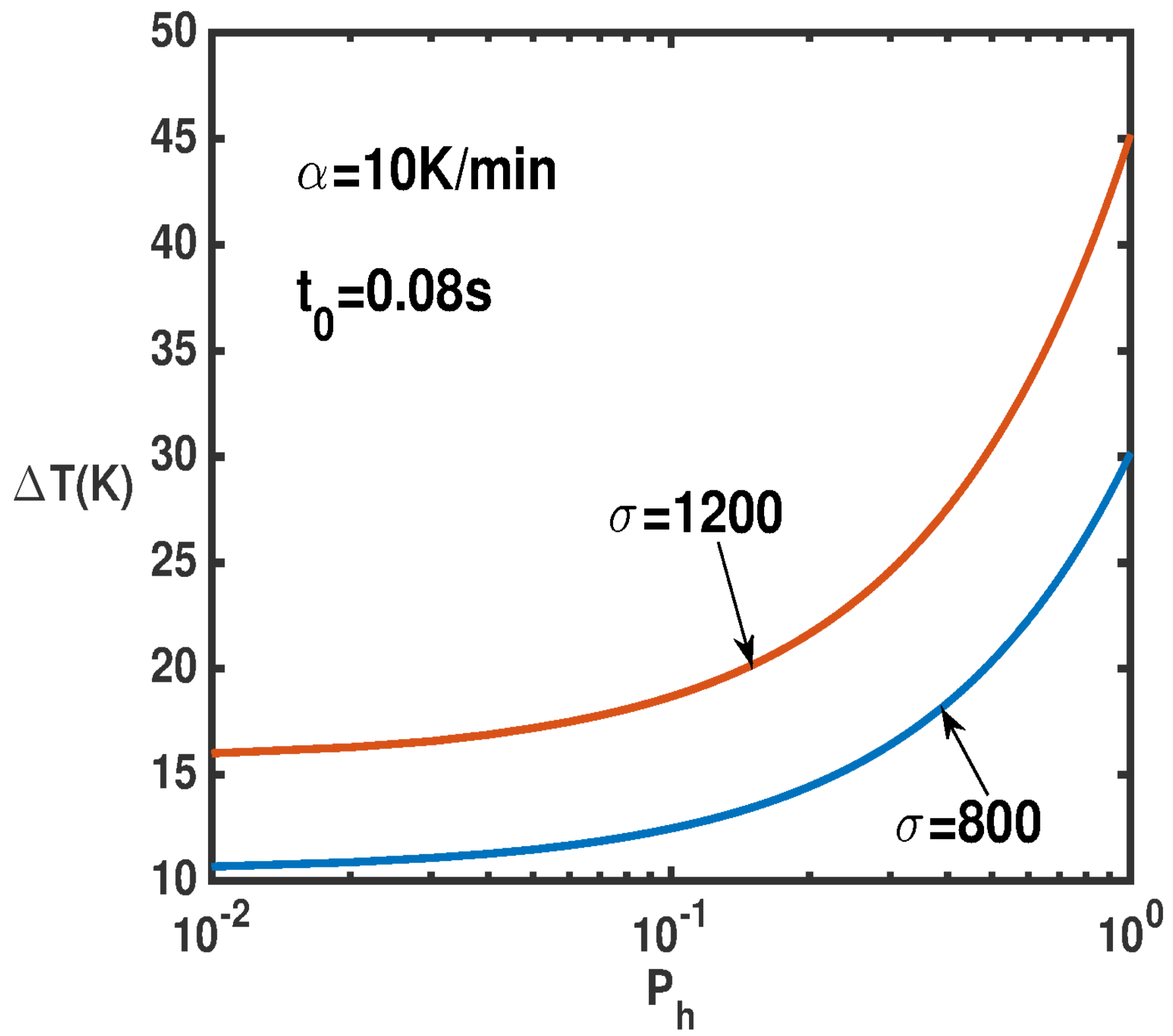

Figure 3: Dependence of width of the dynamic hysteresis loop $\Delta T$ on transverse heat Peclet number $\left(P_{h}\right)$ and $\sigma$ for inlet $C O=100 \mathrm{ppm}$ 


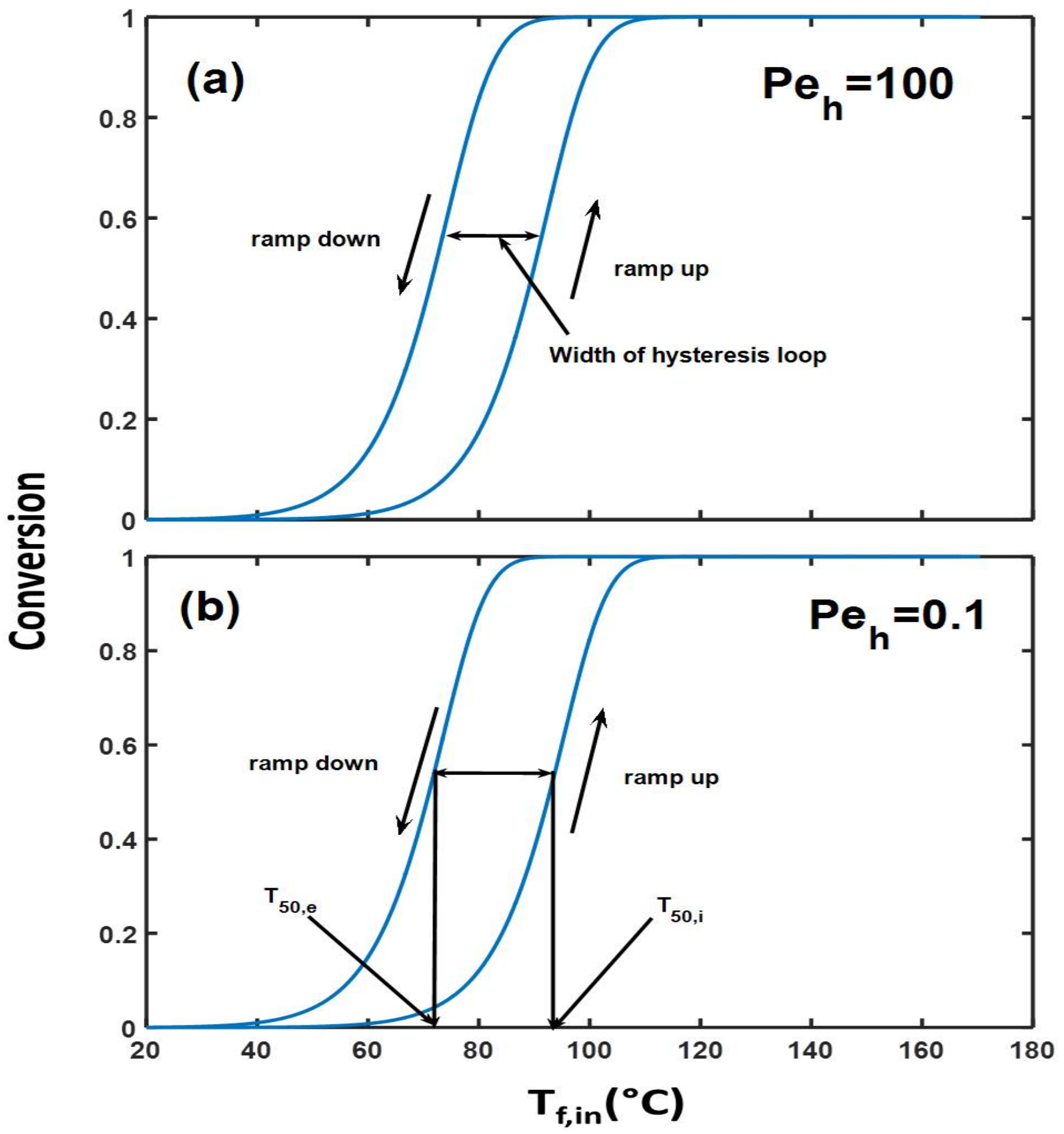

Figure 4: Dependence of the $C O$ conversion on fluid inlet temperature during ramp up and ramp down periods. (ramp rate $=10 \mathrm{~K} / \mathrm{min} ; \sigma=1200 ; t_{0}=0.08 s ; C O=100 \mathrm{ppm}$ ) 


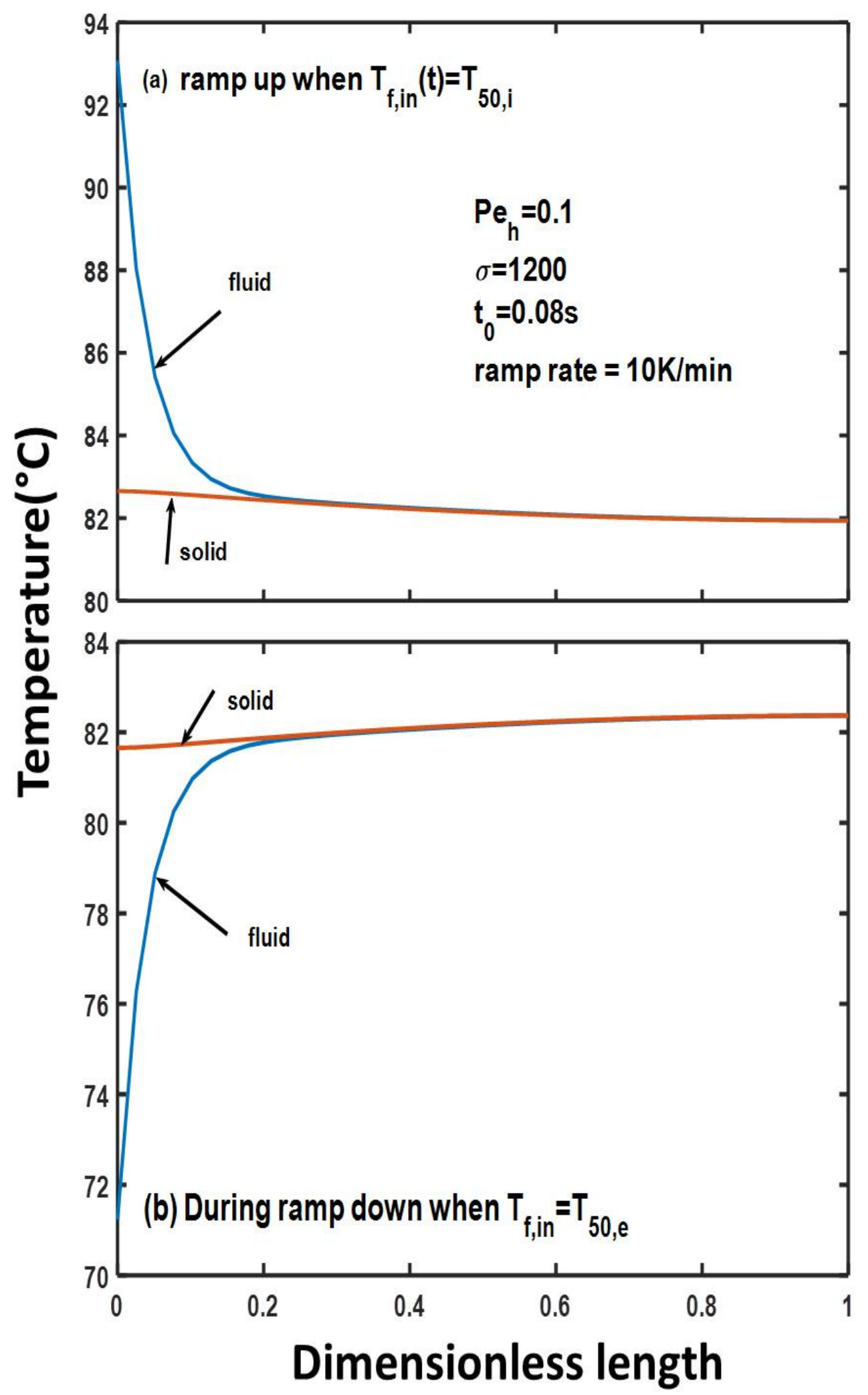

Figure 5: Solid and fluid temperature profiles during (a) ramp up and (b)ramp down. for inlet $C O=100 \mathrm{ppm}$ 


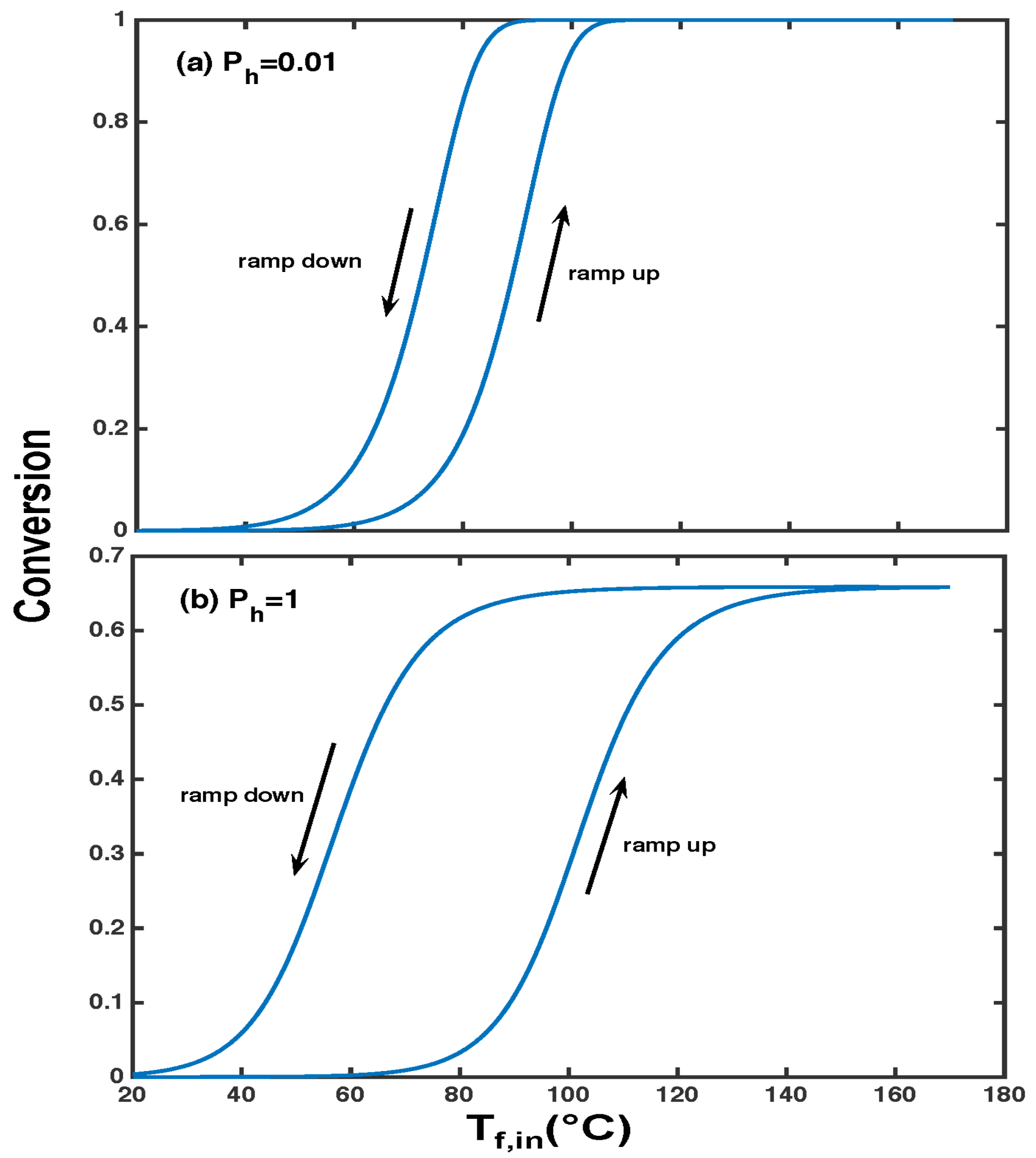

Figure 6: Dependence of the $C O$ conversion on fluid inlet temperature during ramp up and ramp down periods. ( ramp rate $=10 \mathrm{~K} / \mathrm{min} ; \sigma=1200 ; t_{0}=0.08 \mathrm{~s} ; P e_{h}=100 ; C O=100 \mathrm{ppm}$ ) 


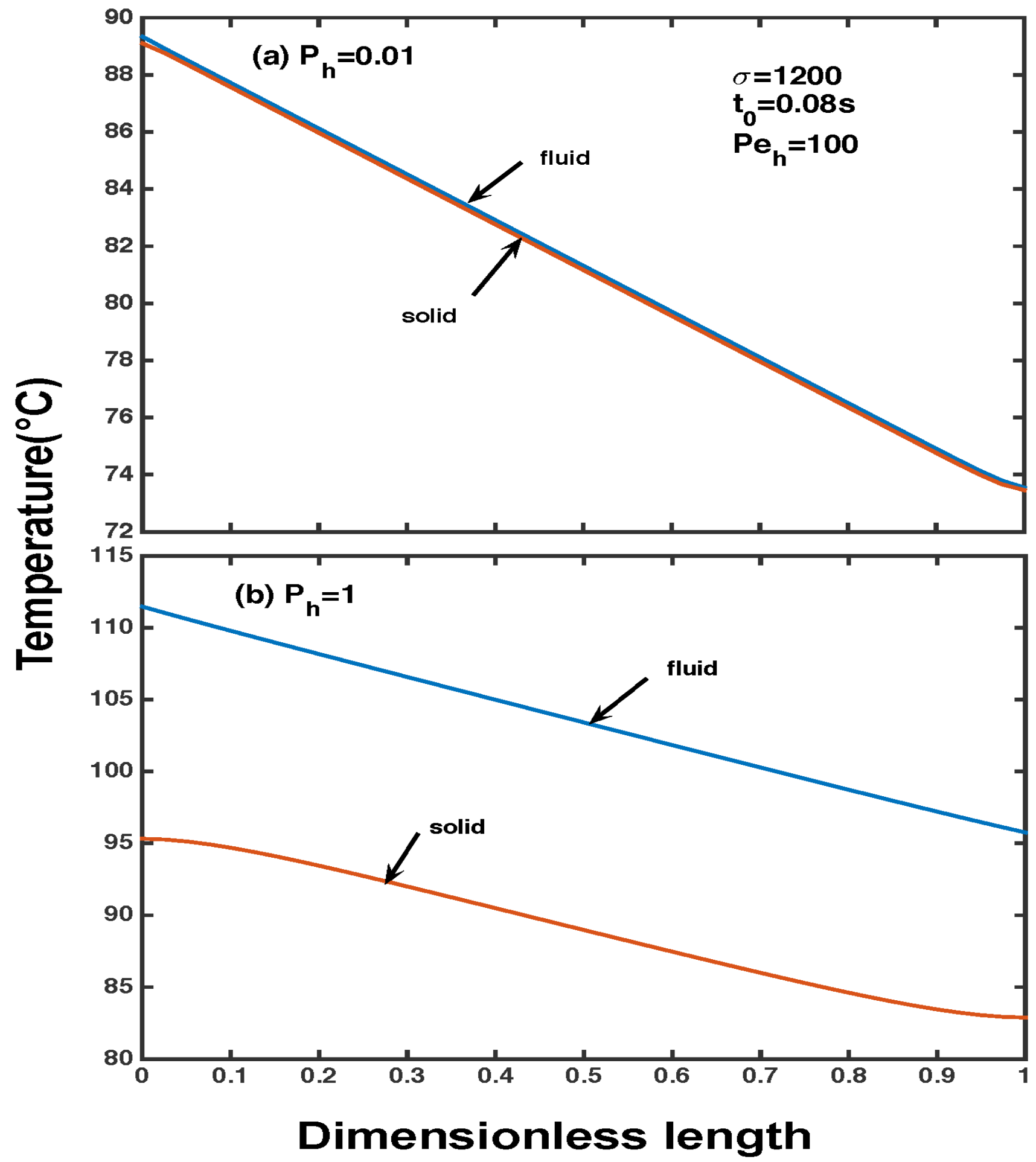

Figure 7: Impact of $\mathrm{P}$ on solid and fluid temperature profiles during ramp up at time t when $T_{f, i n}(t)=T_{50}$ (temperature at which conversion reaches $50 \%$ during ramp up) for inlet $C O=100 \mathrm{ppm}$ 


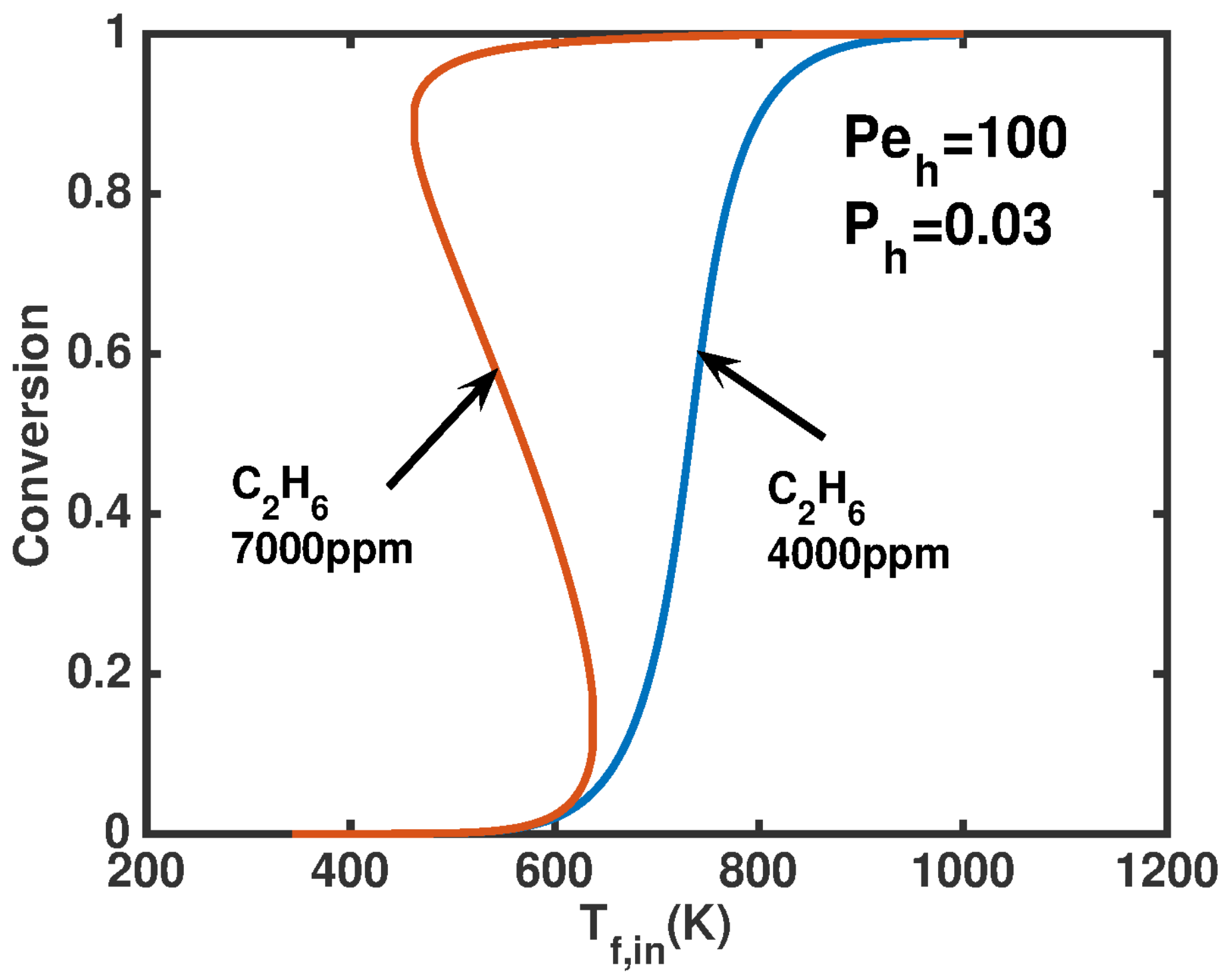

Figure 8: Steady state bifurcation diagrams of conversion versus fluid inlet temperature for different inlet mole fractions of $\mathrm{C}_{2} \mathrm{H}_{6}$. 


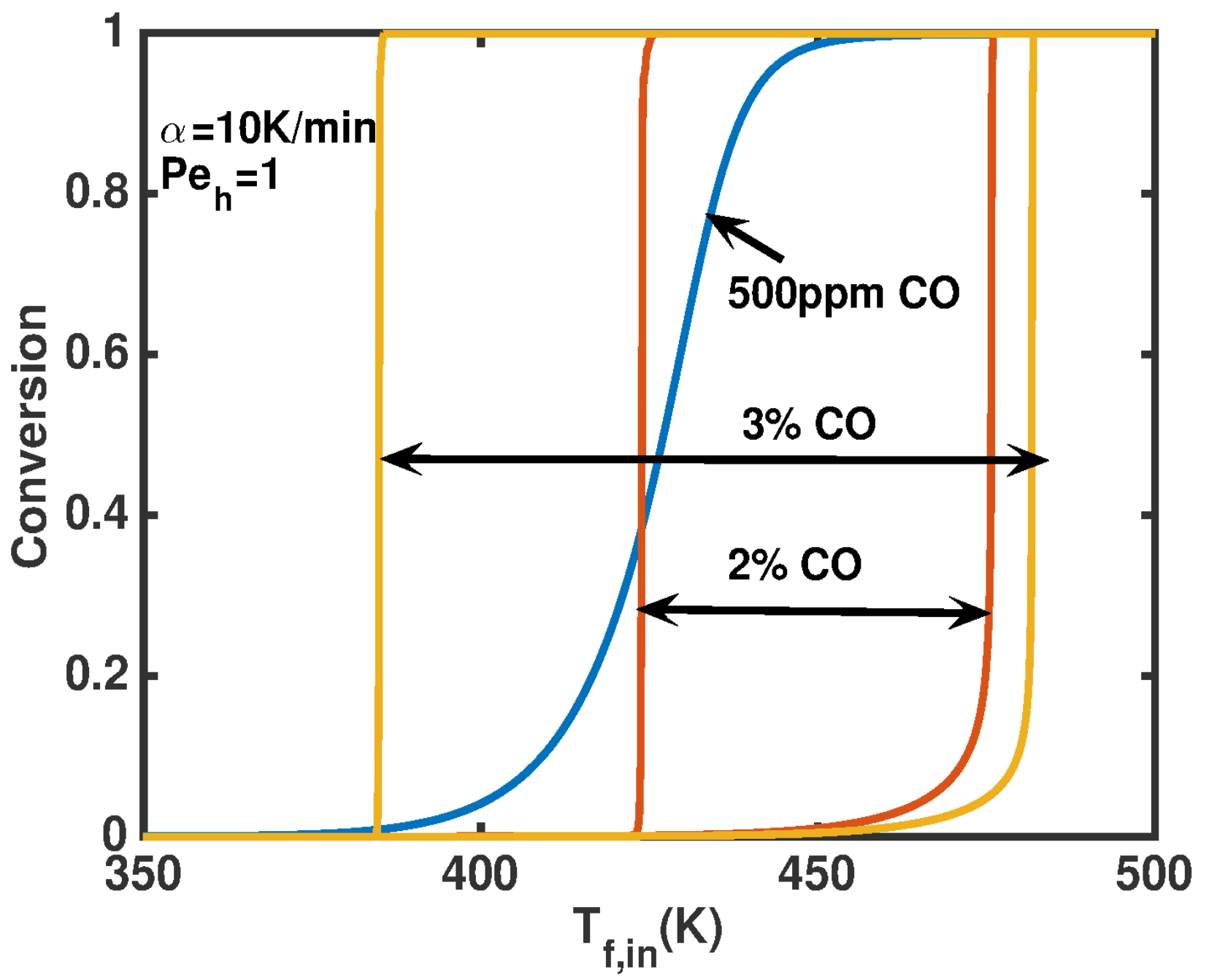

Figure 9: Dependence of the $C O$ conversion on feed temperature during ramp up and ramp down for three different $C O$ inlet concentrations. 


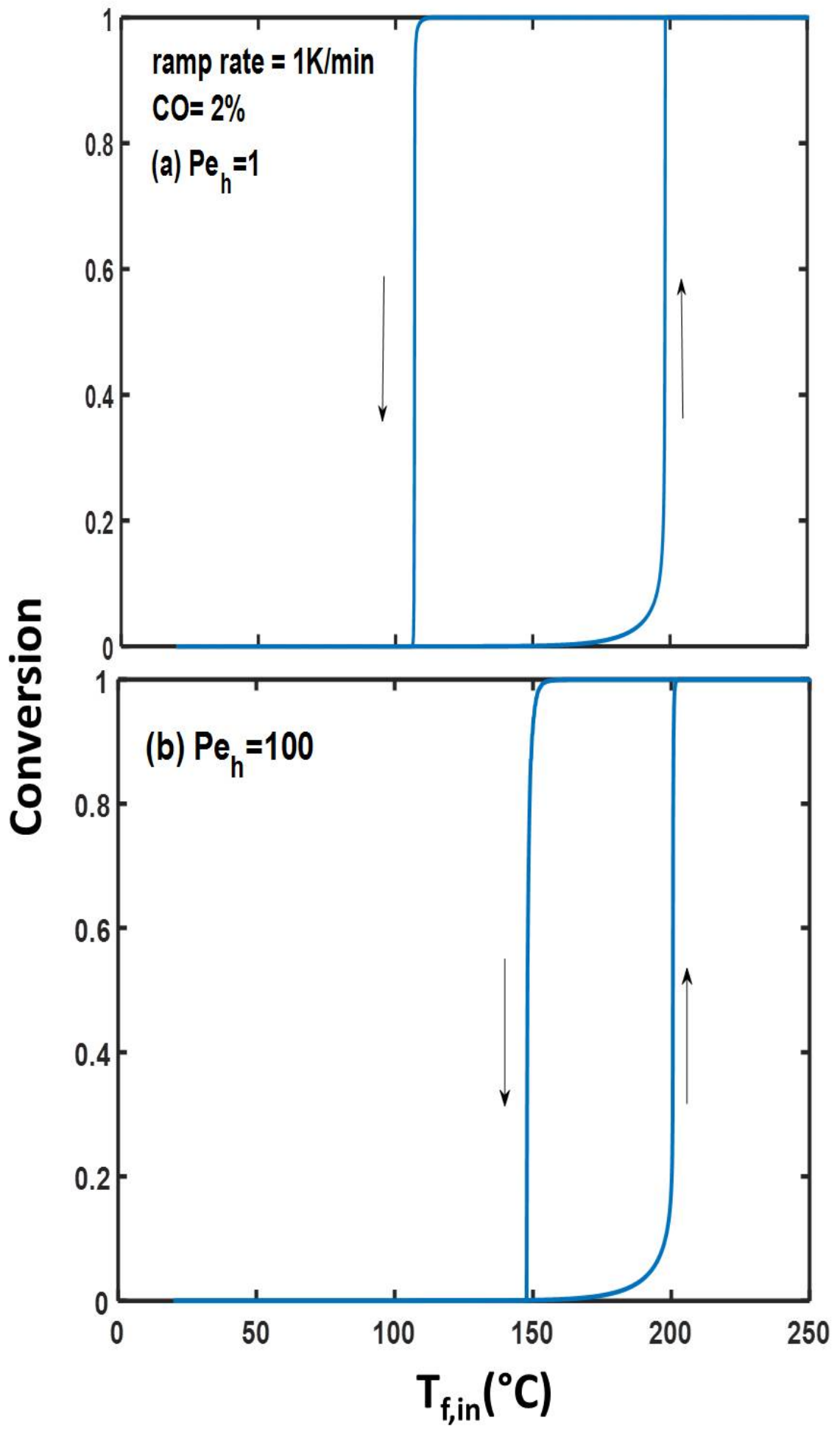

Figure 10: Dependence of $C O$ conversion on $P e_{h}$ and fluid feed temperature during ramp up and ramp down. 


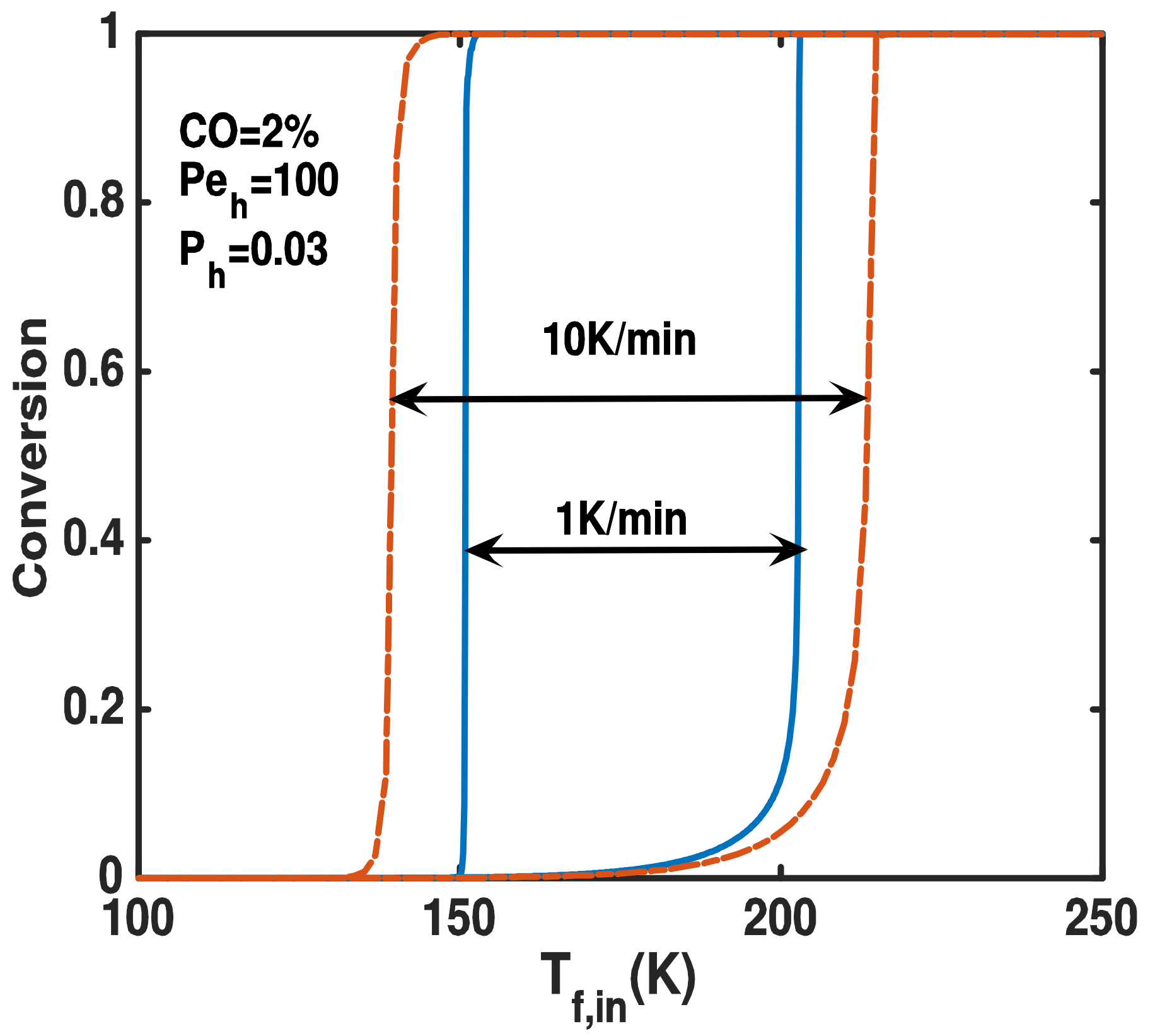

Figure 11: Plot of $C O$ conversion versus inlet fluid temperature illustrating the impact of ramp rate on the dynamic hysteresis behavior. 


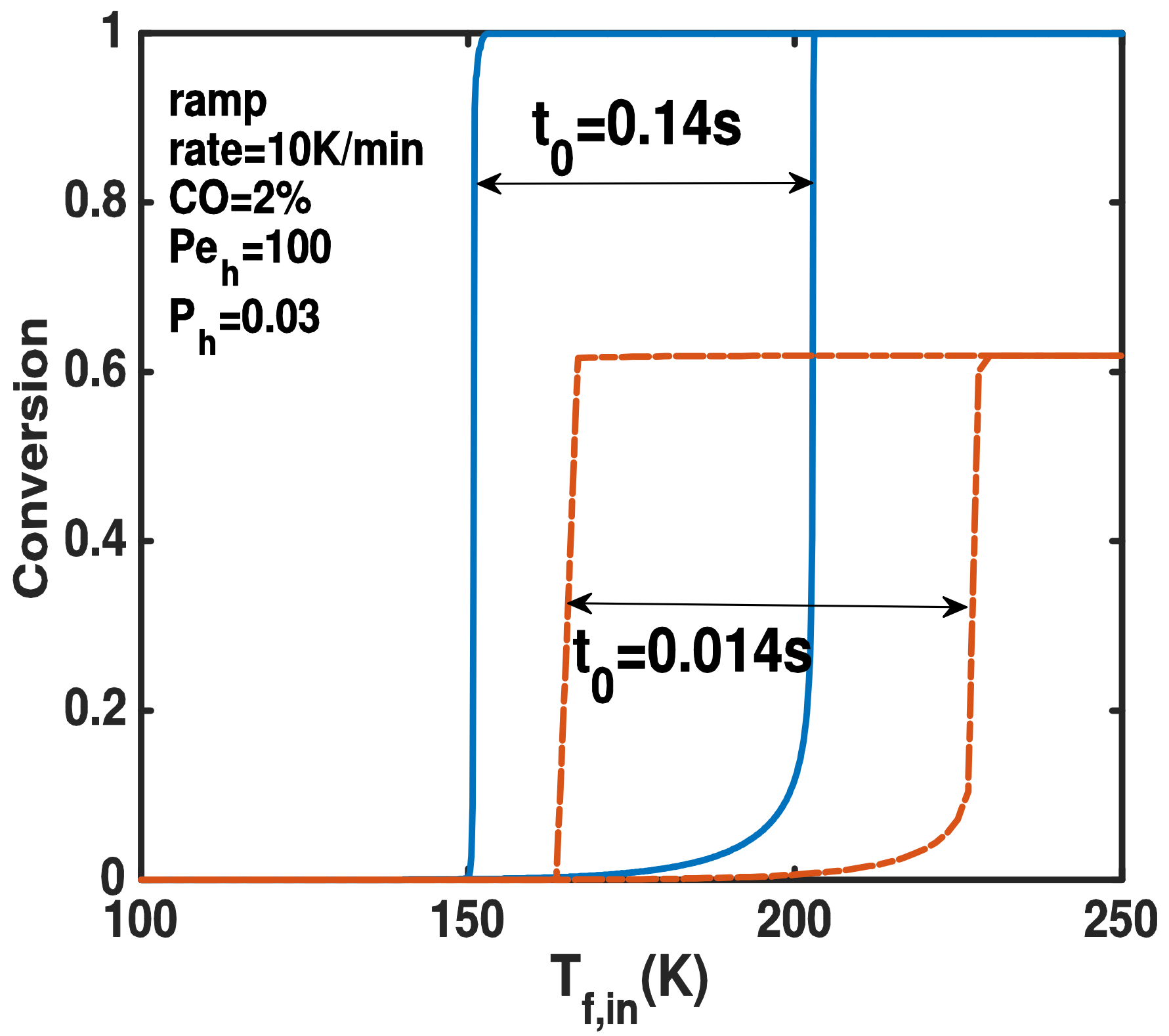

Figure 12: Impact of residence time on the dynamic hysteresis. Conversion versus fluid inlet temperature for different residence times. 


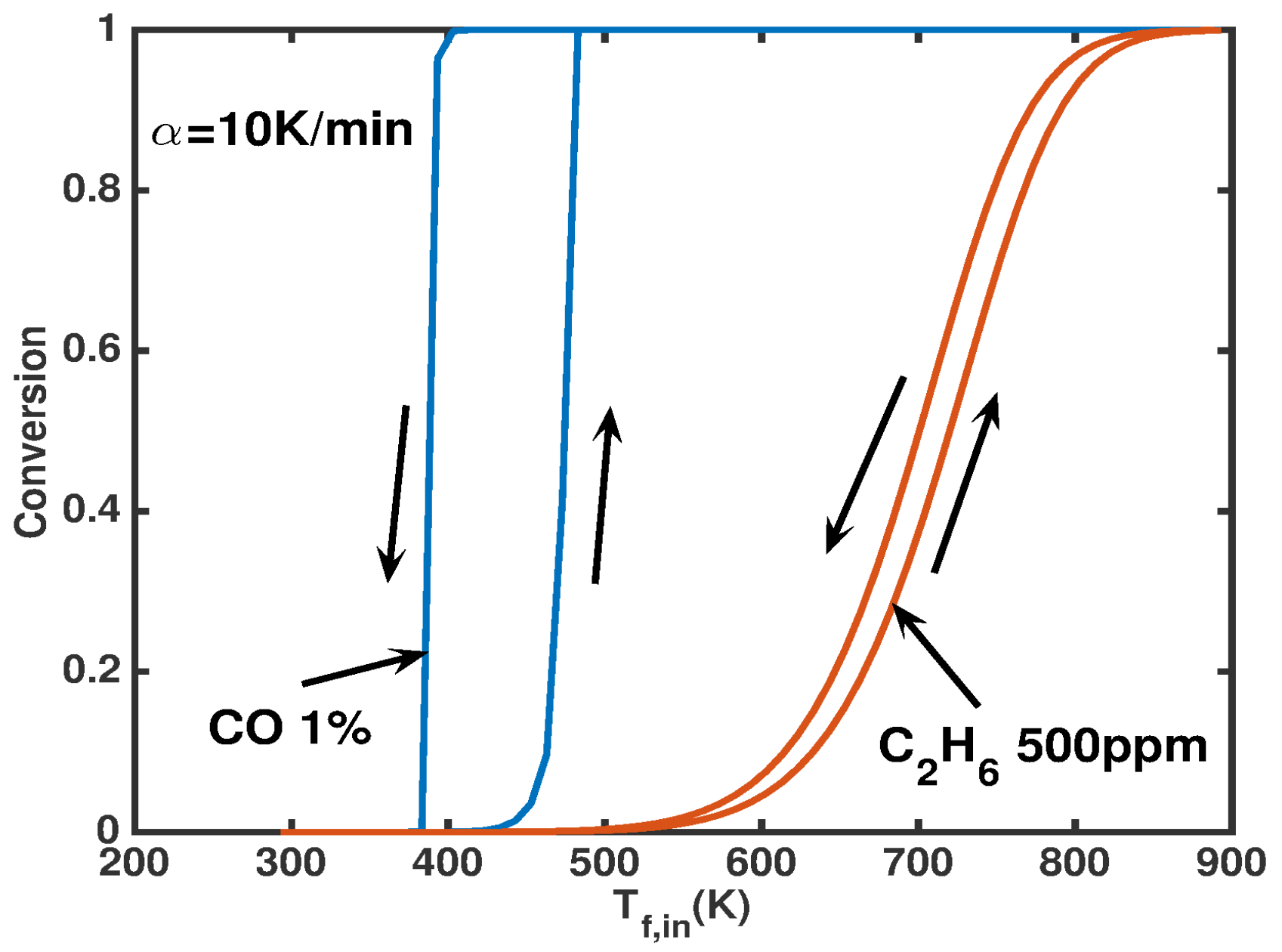

Figure 13: Dependence of conversion on ramped fliud feed temperature for a feed consisting of only $\mathrm{CO}$ or only $\mathrm{C}_{2} \mathrm{H}_{6}$. 


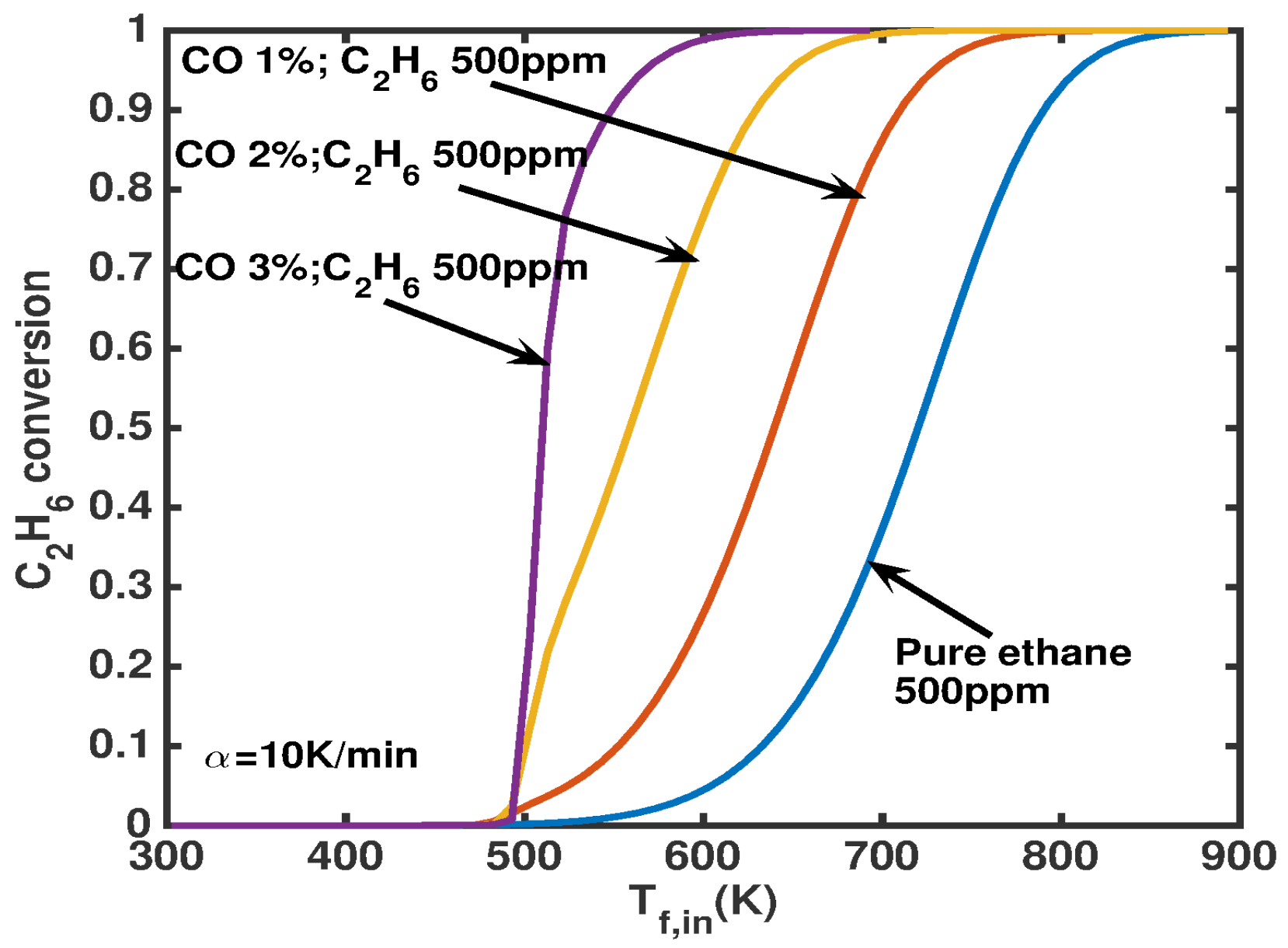

Figure 14: Dependence of ethane conversion on fluid inlet temperature for different inlet mole fractions of $C O$. 


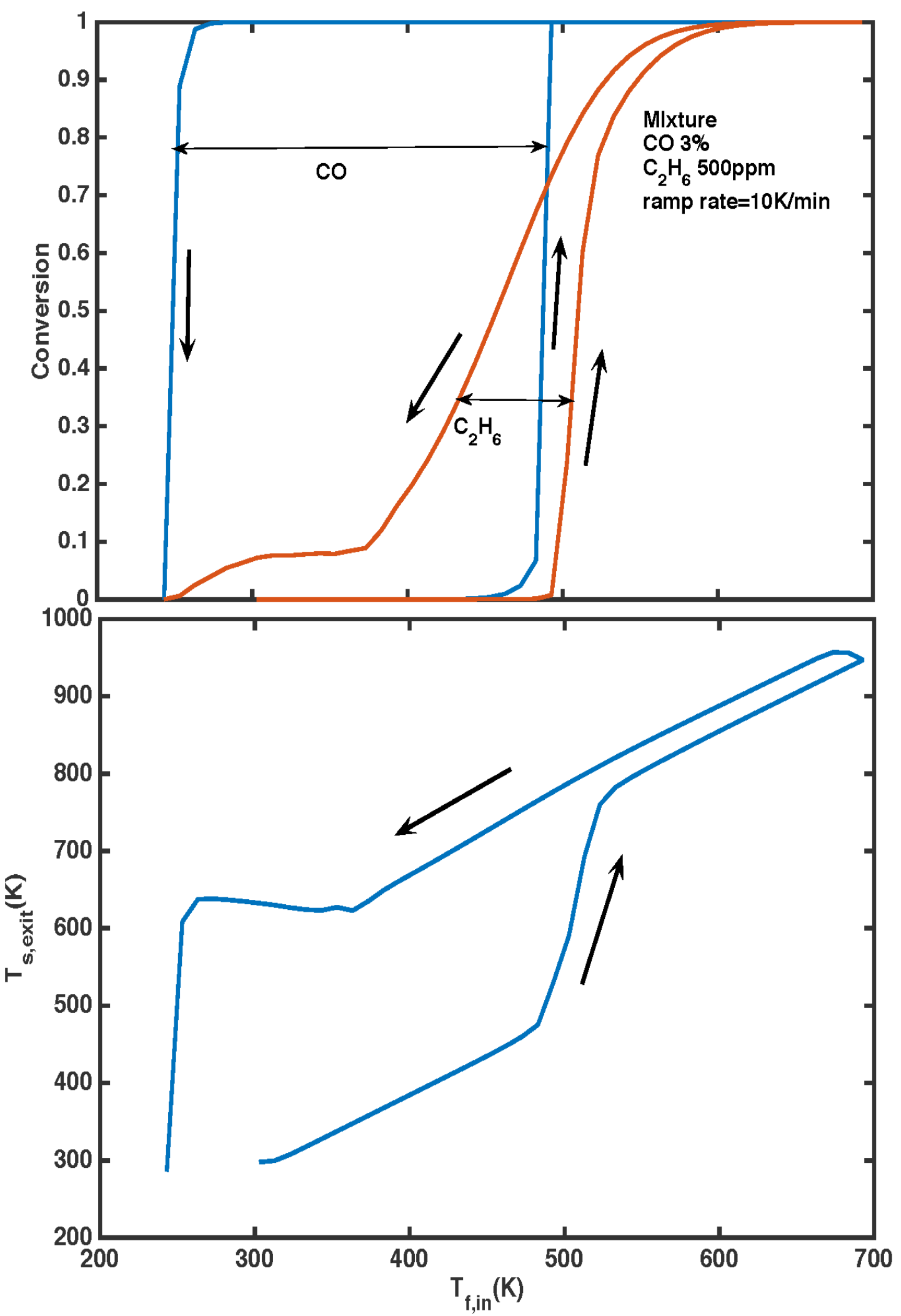

Figure 15: Dependence of conversion and solid exit temperature on fluid inlet temperature. 

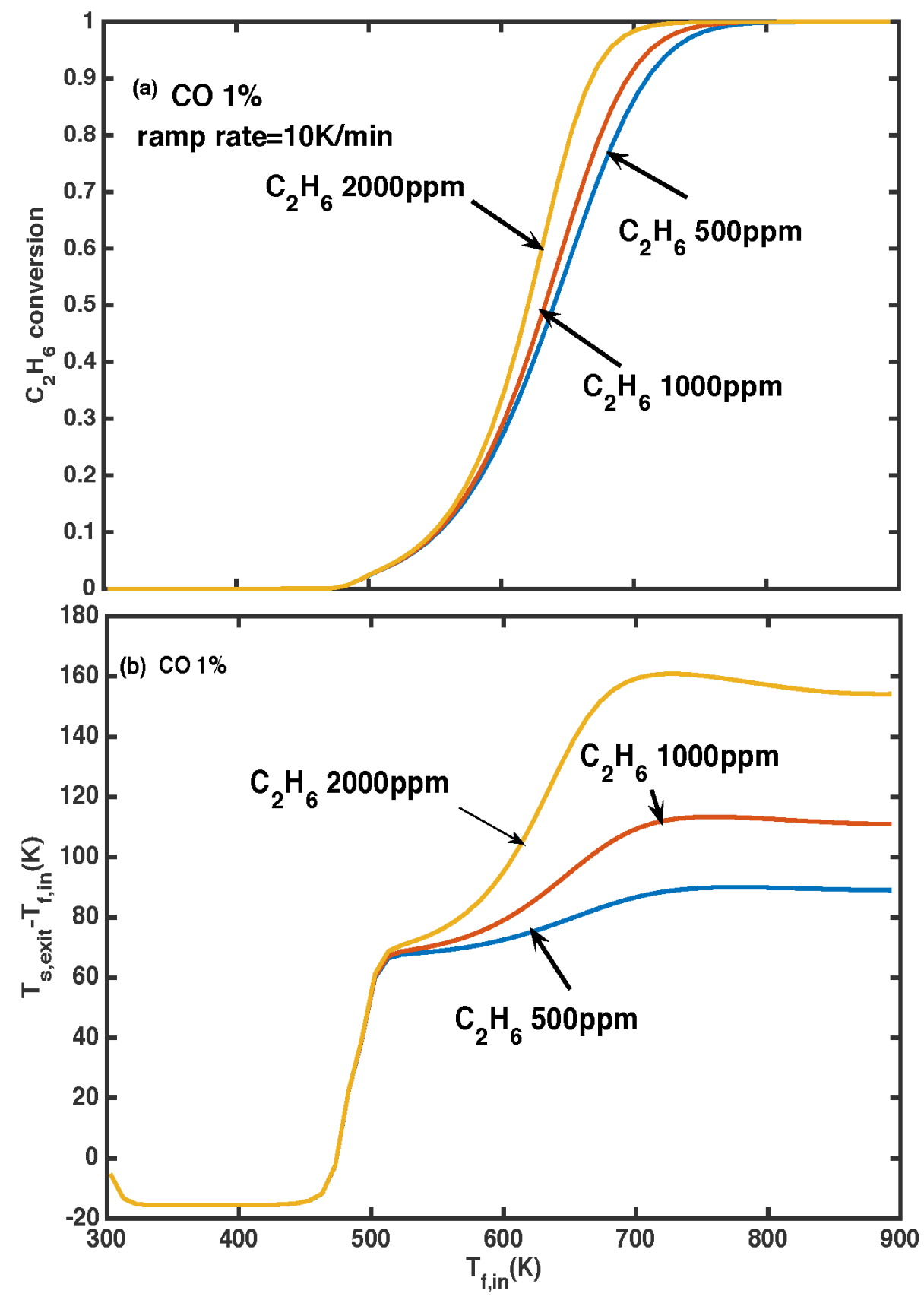

Figure 16: Dependence of conversion and difference of solid exit temperature and fluid inlet temperature for different inlet mole fractions of $\mathrm{C}_{2} \mathrm{H}_{6}$ on fluid inlet temperature. 

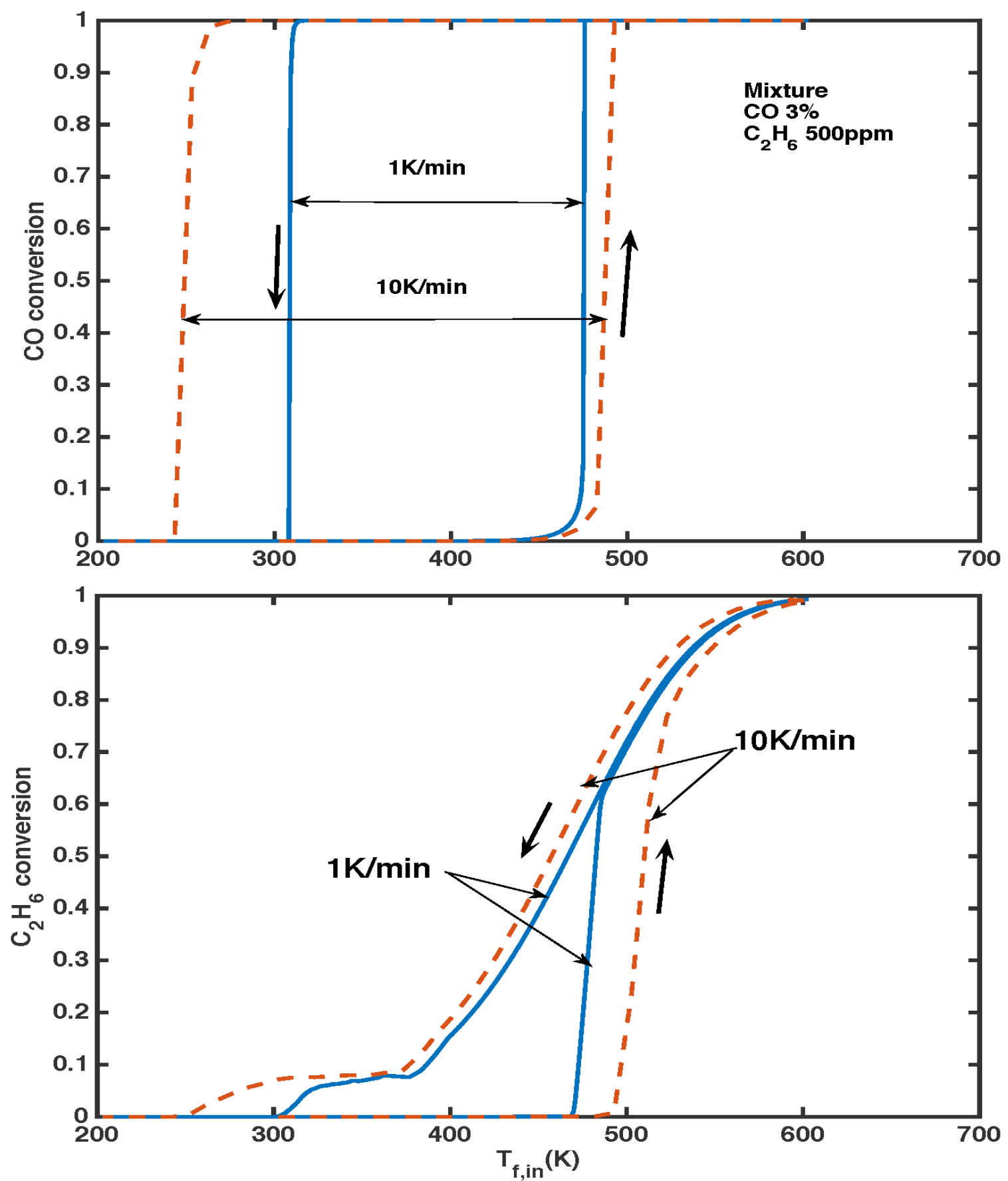

Figure 17: Dependence of $C O$ conversion and $C_{2} H_{6}$ conversion on fluid inlet temperature for two different ramp rates. 
Effect of ramp rate on dynamic hysteresis during co-oxidation of $\mathrm{CO}$ and $\mathrm{C}_{2} \mathrm{H}_{6}$
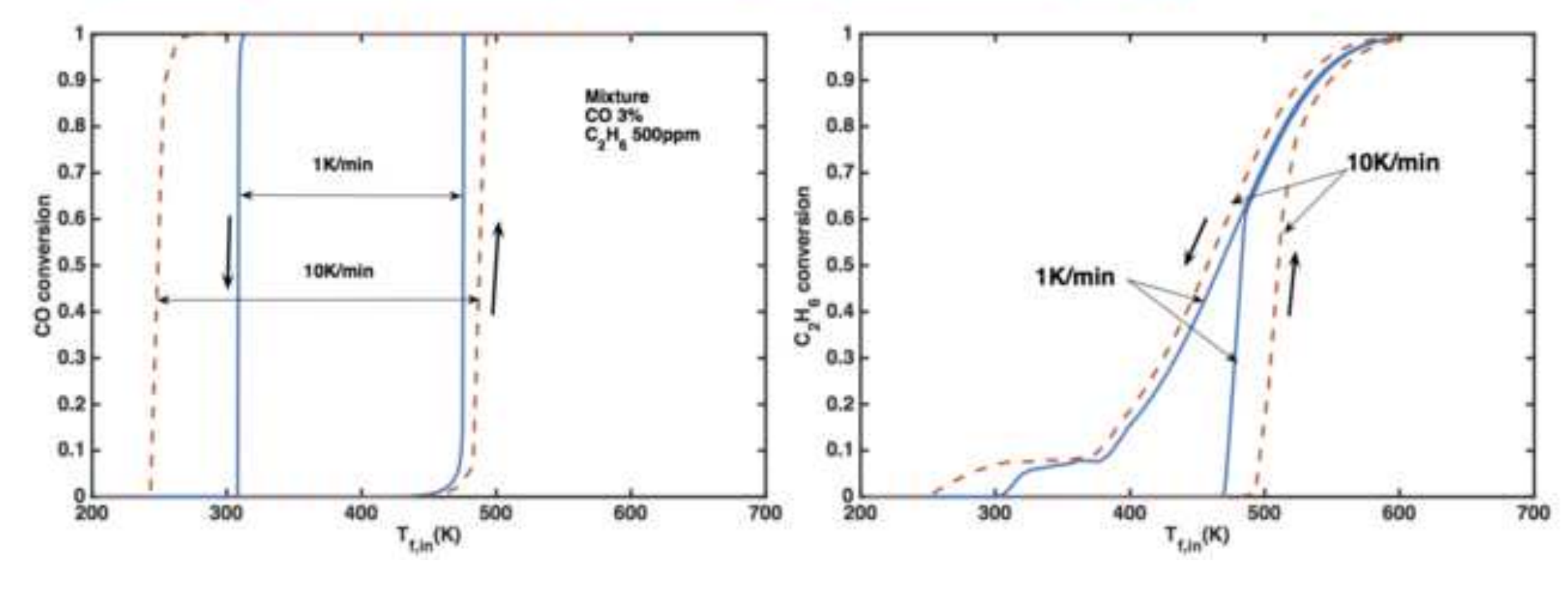

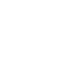

